\title{
Study on the Ratio of Pore-Pressure/Stress Changes During Fluid Injection and Its Implications for $\mathrm{CO}_{2}$ Geologic Storage
}

Seunghee Kim and Seyyed Abolfazl Hosseini

First Author:

Seunghee Kim

Bureau of Economic Geology, Jackson School of Geosciences, The University of Texas at Austin, University Station, Box X, Austin, TX 78713, USA.

*Present address: Department of Civil Engineering, University of Nebraska-Lincoln, The Peter Kiewit Institute, 204C 1110 South $67^{\text {th }}$ St, Omaha, NE 68182, USA.

seunghee.kim@unl.edu

Corresponding Author: Seyyed Abolfazl Hosseini

Bureau of Economic Geology, Jackson School of Geosciences, The University of Texas at Austin, University Station, Box X, Austin, TX 78713, USA.

seyyed.hosseini@beg.utexas.edu

Phone: +1 (512) 471-2360

Fax: +1 (512) 471-0140 


\title{
Study on the Ratio of Pore-Pressure/Stress Changes During Fluid Injection and Its Implications for $\mathrm{CO}_{2}$ Geologic Storage
}

\author{
Seunghee Kim and Seyyed Abolfazl Hosseini
}

\begin{abstract}
The success of fluid injection into geological formations, which is the main operation during both carbon dioxide $\left(\mathrm{CO}_{2}\right)$ geologic storage and wastewater injection, is contingent on the geomechanical integrity of the site. A key task that allows us to evaluate the risk of geomechanical failure is the precise prediction of pore-pressure buildup and subsequent change in the state of stresses during and after the fluid injection. Contrary to traditional approaches, where total stresses are assumed to remain constant, recent studies have ascertained that total stresses in fact change in every direction as fluid extraction/injection disturbs the pore-pressure field and causes deformations. In this study, we conduct an in-depth investigation of the ratio of change in total stress to that in pore-pressure, $\Delta \sigma / \Delta P$, which has been denoted in the literature as the pore-pressure/stress coupling. We employ a numerical simulation method that couples singlephase fluid flow in porous media with poroelasticity to explore the spatiotemporal evolution of the $\Delta \sigma / \Delta P$ ratio for various conditions. These numerical experiments allow us to examine how different material properties and structural geometries would influence the evolution of $\Delta \sigma / \Delta P$ in both vertical and horizontal directions. These ratios of pore-pressure/stress changes exhibit different spatiotemporal evolutions depending on key factors that include the hydraulic boundary condition, Biot's coefficient, Poisson's ratio, and the hydraulic diffusivity of both the injection zone and caprock. On the basis of observations, we suggest firsthand guidelines for analytically determining the ratio of pore-pressure/stress changes, $\Delta \sigma / \Delta P$. Finally, we use examples and case studies to illustrate how the $\Delta \sigma / \Delta P$ ratio can be incorporated into an analytic calculation for determining a maximum sustainable pressure limit.
\end{abstract}


Keywords: Poroelasticity, pore-pressure/stress change ratio, induced seismicity, and $\mathrm{CO}_{2}$ geologic storage 


\section{Introduction}

Carbon Capture, Utilization, and Storage (CCUS) has been actively studied in the last two decades because of its role as a bridge in the transition from a fossil-fuel-dependent system to a renewable-energy-dependent one (Socolow and Pacala, 2006). Geologic carbon storage involves injecting carbon dioxide, which is captured from an emission source and transported to a sequestration site, into a geological formation that is typically deeper than $800 \mathrm{~m}$ (IPCC, 2005). Several challenges remain for the success of geologic carbon dioxide $\left(\mathrm{CO}_{2}\right)$ storage, such as managing field-wide pore-pressure buildup during $\mathrm{CO}_{2}$ injection, enhancing the sweep efficiency of injected $\mathrm{CO}_{2}$, monitoring $\mathrm{CO}_{2}$ migration (Shakiba and Hosseini, 2016; Alfi and Hosseini, 2016; Hosseini and Alfi, 2015)), controlling any possible $\mathrm{CO}_{2}$ leakage, and ensuring the geomechanical integrity of the storage site (Hosseini and Nicot, 2012; Kim and Santamarina, 2013; Kim and Santamarina, 2014; Stauffer et al., 2011). Two of these challenges—maximizing $\mathrm{CO}_{2}$ injectivity and ensuring geomechanical integrity - may conflict with each other. Therefore, it is essential to have a reliable estimate of the initial in situ stress field and a valid prediction of stress paths during $\mathrm{CO}_{2}$ injection to optimize the achievement of these two goals (Rutqvist et al., 2008).

Contrary to traditional approaches where total stresses are assumed to remain constant, recent studies report that total stresses change in response to changes in pore pressure. For example, many petroleum production fields reported that horizontal stresses, $\sigma_{h}$, decreased as pore pressure, $P$, declined during fluid extraction (Addis, 1997; Ferronato et al., 2008; Hillis, 2000; Hillis, 2001; Streit and Hillis, 2004). Stress and pore-pressure measurements from the sites reveal that both stress and pore pressure decreased with a certain ratio that ranges $0.34 \leq \Delta \sigma_{h} / \Delta P$ $\leq 1.18$ (Altmann et al., 2010). Let's examine how stresses would evolve if the ratio $\Delta \sigma_{h} / \Delta P$ is 
reflected during fluid extraction/injection. To simplify the analysis, a hypothetical reservoir under a normal-faulting stress regime (i.e., extensional stress regime) is considered here. During fluid extraction, the Mohr circle would expand rightward and so approach a failure criterion as pore pressure declines (Figure 1a and c, under isothermal conditions - no temperature change is considered). This rationale may explain a number of reported microseismic events during and after petroleum production (Segall and Fitzgerald, 1998). In contrast, the Mohr circle would shrink leftward and so maintain a certain distance from a failure criterion during fluid injection (compare Figure $1 \mathrm{~b}$ and $\mathrm{d}$, under isothermal conditions). Note that this analysis applies only to a reservoir under the normal-faulting stress regime. Stress paths for a reservoir under a reversefaulting or a strike-slip stress regime would exhibit different trajectories (Rutqvist et al., 2008; Vilarrasa et al., 2013b).

It is worth noting that the preceding analysis considers change of pore-pressure disturbance in the horizontal stress only. This approach reflects many previous analyses that found vertical stress changes negligible. However, recent studies have ascertained that total stresses change in every direction as fluid extraction/injection disturbs the pore-pressure field and causes deformations (Altmann et al., 2010; Safari et al., 2013; Schoenball et al., 2010). If this is true, injecting $\mathrm{CO}_{2}$ into a geologic formation would cause both vertical and horizontal stresses to increase as pore pressure builds up in a reservoir. In this case, we need to know the ratio of pore-pressure/stress changes in both directions to properly predict stress paths during fluid injection. These ratios then need to be incorporated for evaluating the maximum sustainable pressure limit that helps to avoid any geomechanical failures and thus undesirable induced seismic events. However, no previous study has investigated how the ratio of pore- 
pressure/stress changes develops with injection time at different locations for various material and geometrical conditions.

In this manuscript, we present a brief review of theoretical background that elucidates stress changes coupled with pore-pressure disturbance based on linear poroelastic theory (Biot, 1962; Wang, 2000). We conduct an in-depth investigation of the ratio of change in total stress to change in pore pressure $\Delta \sigma / \Delta P$ (which has been described as pore-pressure/stress coupling in much of the literature). We employ numerical simulations that couple single-phase fluid flow in porous media with poroelasticity to explore spatiotemporal evolution of the $\Delta \sigma / \Delta P$ ratio for various conditions. Note that our main objective is to investigate large-scale geomechanical changes, not pore-pressure buildup itself; this simpler model facilitates focusing on the poroelastic effect (Rutqvist, 2012). These numerical experiments allow us to examine the effect of material properties and structural geometries on the evolution of $\Delta \sigma / \Delta P$ in both vertical and horizontal directions. On the basis of observations, we suggest firsthand guidelines for analytically determining the ratio of pore-pressure/stress changes, $\Delta \sigma / \Delta P$. Finally, we offer examples and case studies to illustrate how these $\Delta \sigma / \Delta P$ ratios can be incorporated into an analytic calculation for determining a maximum sustainable pressure limit to minimize the risk of undesirable induced seismic events during $\mathrm{CO}_{2}$ injection at a storage site. All analytical computations and numerical simulations in this manuscript assume isothermal fluid-injection conditions. Poroelastic analyses for nonisothermal conditions can be found elsewhere (e.g., single-phase fluid flow (De Simone et al., 2013; Goodarzi et al., 2010; Kim and Hosseini, 2015; Kim and Hosseini, 2014; Neuzil, 2003); two-phase fluid flow (Preisig and Prévost, 2011; Vilarrasa et al., 2014; Vilarrasa et al., 2013b)). 


\section{Analytical Solution: Ratio of Pore-Pressure/Stress Changes}

Here, we briefly show theoretical equations that demonstrate the correlation between changes in pore pressure and stress in porous media. A closed-form solution for this correlation, even if limited to a simple setting, can be very useful for many underground problems such as soil consolidation (Biot, 1941), hydraulic fracturing (Detournay et al., 1989), reverse water-level fluctuation (Verruijt, 1969), and ground upheaval (Selvadurai, 2009). The analytical derivation herein is described based on the work by Rudnicki (Rudnicki, 1986). For a saturated linearelastic porous medium, change in the total stress tensor $\sigma_{i j}$ is related to the displacement gradient $u_{i, j}=\partial u_{i} / \partial x_{j}$ and change in pore fluid pressure $P$ :

$$
\sigma_{i j}=G\left(u_{i, j}+u_{j, i}\right)+\lambda u_{k, k} \delta_{i j}-\alpha P \delta_{i j}
$$

where $\lambda$ and $G$ are the Lame parameters of linear elasticity, $\alpha$ is Biot's coefficient, and $\delta_{i j}$ is the Kronecker delta. (Note: Rudnicki's work follows a sign convention of continuum mechanics, i.e., tensile stress is positive.) Another constitutive equation relates change in the fluid mass content per unit volume $m$ of a porous medium with the displacement and pore pressure:

$$
m-m_{0}=\alpha \rho_{f}\left[u_{k, k}+\alpha P /\left(\lambda_{u}-\lambda\right)\right]
$$

where $m_{0}$ is the reference value of $m, \rho_{f}$ is the mass density of pore fluid, and $\lambda_{u}$ is the Lame parameter for an undrained condition. Darcy's law describes mass flow rate $q_{i}$ per unit area in the $x_{i}$ direction as a function of intrinsic permeability $k$, fluid viscosity $\eta$, and the pressure gradient. In the absence of body force, it can be expressed as:

$$
q_{i}=-\rho_{f} \frac{k}{\eta} \frac{\partial P}{\partial x_{i}}
$$


The force equilibrium equation can be expressed in a compact notation as:

$$
\frac{\partial \sigma_{i j}}{\partial x_{i}}+F_{j}=0
$$

where $F_{j}$ denotes a component of body force. As a last component to complete the set of equations, continuity is expressed with change in the fluid mass and a source of fluid mass $Q$ :

$$
\nabla \cdot q+\frac{\partial m}{\partial t}=Q(x, t)
$$

Combining Darcy's law (Equation 3) with fluid mass conservation (Equation 5), the equilibrium equation (Equation 4), and two constitutive equations (Equations 1 and 2) yields the diffusion equation (Cleary, 1977):

$$
\frac{\partial m}{\partial t}=c \nabla^{2} m+\left\{Q(x, t)+\left[\rho_{f} k\left(\lambda_{u}-\lambda\right) / \alpha \eta\left(\lambda_{u}+2 G\right)\right] F_{k, k}\right\}
$$

Diffusivity $c$ is defined using geomechanical and hydraulic properties of a porous medium (Rudnicki, 1986; Wang, 2000):

$$
c=\frac{k\left(\lambda_{u}-\lambda\right)(\lambda+2 G)}{\alpha^{2} \eta\left(\lambda_{u}+2 G\right)}=\frac{k}{\eta} \frac{2 G(1-v)}{(1-2 v)}\left[\frac{B(1+v)}{3 \alpha(1-v)-2 B \alpha^{2}(1-2 v)}\right]
$$

where $v$ is Poisson's ratio under a drained condition, and $B$ is Skempton's coefficient. If a fluid is injected at a point with a constant rate $q$ into an infinite homogeneous poroelastic medium in the spherically symmetric domain, the solutions for Equation 6 are obtained as follows (Rudnicki, 1986):

$$
\text { Change in the fluid mass: } m(x, t)=\frac{q}{4 \pi c r} \operatorname{erfc}\left(\frac{1}{2} \xi\right)
$$




$$
\begin{aligned}
& \text { Displacement: } u_{i}(x, t)=\frac{q}{\rho_{f} c} \frac{x_{i}}{r}\left[\frac{\lambda_{u}-\lambda}{8 \pi \alpha\left(\lambda_{u}+2 G\right)}\right]\left(\operatorname{erfc}\left(\frac{1}{2} \xi\right)+\frac{2}{\xi^{2}} g(\xi)\right) \\
& \text { where } g(\xi)=\frac{1}{2 \sqrt{\pi}} \int_{0}^{\xi} s^{2} \exp \left(-\frac{1}{4} s^{2}\right) d s=\operatorname{erf}\left(\frac{1}{2} \xi\right)-\frac{\xi}{\sqrt{\pi}} \exp \left(-\frac{1}{4} \xi^{2}\right)
\end{aligned}
$$

where radial distance is $r=\left(x_{k} x_{k}\right)^{1 / 2}$, Boltzmann variable is $\xi=r /(c t)^{1 / 2}$, and complementary error function is $\operatorname{erfc}(z)=1-\operatorname{erf}(z)$. Changes in pore pressure and stresses can be calculated using Equation 9 and constitutive equations (Altmann et al., 2010; Rudnicki, 1986):

$$
\begin{gathered}
P(x, t)=\frac{q}{\rho_{f} c} \frac{1}{4 \pi r}\left[\frac{\left(\lambda_{u}-\lambda\right)(\lambda+2 G)}{\alpha^{2}\left(\lambda_{u}+2 G\right)}\right] \operatorname{erfc}\left(\frac{1}{2} \xi\right) \\
\sigma_{i j}(x, t)=-\frac{q}{\rho_{f} c} \frac{\left(\lambda_{u}-\lambda\right) G}{4 \pi r \alpha\left(\lambda_{u}+2 G\right)}\left\{\delta_{i j}\left[\operatorname{erfc}\left(\frac{1}{2} \xi\right)-\frac{2}{\xi^{2}} g(\xi)\right]+\frac{x_{i} x_{j}}{r^{2}}\left[\operatorname{erfc}\left(\frac{1}{2} \xi\right)+\frac{6}{\xi^{2}} g(\xi)\right]\right\}
\end{gathered}
$$

Equations 10 and 11 directly indicate that changes in pore pressure and stresses vary as a function of distance from an injection point, elapsed time, injection rate, diffusivity, and other poroelastic properties. Furthermore, the ratio of change in stress and pore-pressure $\Delta \sigma / \Delta P$ can be expressed using these equations (note that the sign has changed; compression is now defined as positive):

$$
\frac{\Delta \sigma_{i j}(x, t)}{\Delta P(x, t)}=\frac{\alpha(1-2 v)\left\{\delta_{i j}\left[\operatorname{erfc}((1 / 2) \xi)-\left(2 / \xi^{2}\right) g(\xi)\right]+\left(x_{i} x_{j} / r^{2}\right)\left[\operatorname{erfc}((1 / 2) \xi)+\left(6 / \xi^{2}\right) g(\xi)\right]\right\}}{2(1-v) \operatorname{erfc}((1 / 2) \xi)}
$$

Equation 12 implies that the ratio of change in stress and pore-pressure $\Delta \sigma / \Delta P$ evolves on a spatiotemporal scale. Moreover, it shows that two parameters, Biot's coefficient $\alpha$ and Poisson's ratio $v$, determine the absolute value of ratio $\Delta \sigma / \Delta P$, whereas Boltzmann variable $\xi$ affects how the $\Delta \sigma / \Delta P$ evolves before reaching its absolute value. For a homogeneous infinite medium, ratios 
of stress and pore-pressure changes converge to $\Delta \sigma_{\mathrm{rad}} / \Delta P=\alpha \cdot(1-2 v) /(1-v)$ and $\Delta \sigma_{\text {tan }} / \Delta P=(\alpha / 2) \cdot(1-$ $2 v) /(1-v)$, radial and tangential directions from the point source, respectively. These terminal values were defined as long-term limit solutions (Altmann et al., 2010). Refer to Safari et al. for a summary of static analytical solutions for other reservoir shapes (Safari et al., 2013).

\section{Numerical Simulation}

The analytical solution for the ratio of change in stress to change in pore pressure $\Delta \sigma / \Delta P$ (Equation 12) is valid for a point injection in homogeneous infinite isotropic poroelastic media (Altmann et al., 2010). In a real application, however, material properties between geologic formations — including a $\mathrm{CO}_{2}$ storage aquifer and surrounding strata—are different. The analytic solution is for the spherical domain, but property contrasts and fluid injection over the entire thickness of the storage aquifer indicate that the cylindrical domain is more appropriate. Moreover, because structural geometry and boundary conditions also affect the evolution of $\Delta \sigma / \Delta P$ during fluid injection, we implemented numerical simulations to explore the spatiotemporal evolution of $\Delta \sigma / \Delta P$ for various conditions.

\subsection{Simulation Method}

We used the commercial software COMSOL to investigate the ratio of porepressure/stress changes during fluid injection into a storage aquifer. The single-phase fluid-flow condition was employed because it suffices to explore the poroelastic coupling between changes in pore pressure and stresses (Rutqvist, 2012), which is also the reason that only isothermal conditions are considered in this study. If the main purpose is to investigate pore-pressure buildup itself driven by $\mathrm{CO}_{2}$ injection, two-phase fluid flow should be employed because the partial miscibility and capillarity alter the overpressure pattern (see example - (Okwen et al., 
2011)). The subsurface flow module in COMSOL contains predefined sets of equations for the application of Earth-science-related problems (COMSOL, 2012). In this module, two sets of constitutive equations for poroelasticity are combined with force equilibrium, mass continuity, and Darcy's law. Among the predefined sets of equations, the first constitutive equation relates stress tensor $\sigma$, strain tensor $\varepsilon$, and pore fluid pressure $P$ :

$$
\sigma=\vec{C} \varepsilon-\alpha P \vec{I}
$$

Elasticity matrix $\vec{C}$ in Equation 13 refers to a drained condition, and $\vec{I}$ is an identity matrix. The second constitutive equation relates the increment in fluid content $\zeta$ to volumetric strain $\varepsilon_{v o l}$ :

$$
P=M\left(\zeta-\alpha \varepsilon_{v o l}\right)
$$

where Biot's modulus $M$ is the inverse of the storage coefficient $S$, which is a function of porosity $\varphi$, Biot's coefficient $\alpha$, fluid bulk modulus $K_{f}$, and drained bulk modulus $K_{d}$ :

$$
S=\frac{\varphi}{K_{f}}+(\alpha-\varphi) \frac{1-\alpha}{K_{d}}
$$

The fluid equation comes from mass conservation:

$$
\frac{\partial}{\partial t}\left(\rho_{f} \varphi\right)+\nabla \cdot\left(\rho_{f} \vec{u}\right)=Q
$$

where Darcy's velocity $\vec{u}$ and the storage model are:

$$
\begin{aligned}
& \vec{u}=-\frac{k}{\eta}\left(\nabla P+\rho_{f} g \nabla z\right) \\
& \frac{\partial}{\partial t}\left(\rho_{f} \varphi\right)=\rho_{f} S \frac{\partial P}{\partial t}
\end{aligned}
$$


where $z$ is a vertical coordinate. These equations can be translated into the diffusion formulation:

$$
\rho_{f} S \frac{\partial P}{\partial t}+\nabla \cdot \rho_{f}\left[-\frac{k}{\eta}\left(\nabla P+\rho_{f} g \nabla z\right)\right]=-\rho_{f} \alpha \frac{\partial \varepsilon_{v o l}}{\partial t}
$$

Lastly, solid deformation complies with force equilibrium:

$$
\nabla \cdot \sigma+\left(\rho_{f} \varphi+\rho_{d}\right) \vec{g}=\overrightarrow{0}
$$

where $\rho_{d}$ denotes dry density of a porous medium. Equations 13-16 and 19-20 are coupled during the numerical simulation, and computation iterates among these equations at each time step using a finite-element method. The numerical simulation method was validated via comparing its results with those from analytical solutions described by Altmann et al. (2010). Figure 2 shows that the numerical simulation method in this study yields results that are identical to those from the analytical solution (Equation 12) for a homogeneous porous medium model, thus verifying the simulation method.

\section{$\underline{\text { 3.2 Simulation Model and Parameters }}$}

The main objective of this study is to examine spatiotemporal variation of the porepressure/stress change ratio $\Delta \sigma / \Delta \mathrm{P}$ when the geometry is neither infinite nor homogeneous. To simulate linear fluid injection rather than point injection, which is more realistic, we built a simple simulation model (Figure 3) and conducted many numerical "experiments" for various conditions.

The left end of the model is an axis of symmetry. A constant fluid-injection rate is imposed on the left end of the injection zone during the numerical simulation while gravity is 
turned off. Depth to the top of the injection zone, the only stratum in the model with a high permeability value, is $1000 \mathrm{~m}$. Thickness of the injection zone is set to $100 \mathrm{~m}$.

The right end of the injection zone is set either as a fluid outlet or closed boundary, in order to investigate the impact of boundary conditions. The top and bottom ends of the model are set as no-flow boundaries. In terms of mechanical boundary conditions, rollers are imposed on the left and right ends and at the bottom of the model (i.e., only translational displacement is allowed). The top surface is free to move. The vertical boundary is $2 \mathrm{~km}$ away from the top. The radial boundary is also set as $2 \mathrm{~km}$ away from the left end to investigate the deviation in the horizontal stress change from the analytical solution that assumes a thin, laterally extensive reservoir (i.e., a passive basin; Rutqvist, 2012).

Identical or different values of Poisson's ratio, ranging from 0.05 to 0.4 , are assigned to the injection zone and confining layers for each realization to examine the ratio's influence. The upper caprock that overlies the injection zone is assigned a permeability of either $k_{c a p}=1 \mathrm{nd}\left(\approx 10^{-}\right.$

${ }^{21} \mathrm{~m}^{2}$, almost impermeable) or $k_{c a p}=1 \mu \mathrm{d}\left(\approx 10^{-18} \mathrm{~m}^{2}\right.$, somewhat permeable, but less permeable than the injection zone); the other layer below the injection zone is fixed with $k=1$ nd. Permeability of the injection zone is given either $k_{I Z}=10 \mathrm{md}$ or $100 \mathrm{md}$. Lastly, a hydraulic barrier (e.g., an impermeable fault) is inserted into the injection zone at several realizations to investigate the barrier's effect on the evolution of $\Delta \sigma / \Delta P$. Table 1 summarizes all input parameters applied for these various realizations.

\section{Numerical Experiment: Results and Discussion}

In this section, we present numerical simulation results that shed light on the influence of several factors-including material properties, boundary conditions, and the existence of 
hydraulic barriers - on the ratio of pore-pressure/stress change $\Delta \sigma / \Delta P$. Focus is on two stress ratios: (1) the ratio of change in total radial stress to change in pore pressure $\Delta \sigma_{r} / \Delta P$, and (2) the ratio of change in total vertical stress to change in pore pressure $\Delta \sigma_{z} / \Delta P$ for the axisymmetric simulation model. Compression is positive for stresses, as it is in traditional geotechnical engineering. We also focus primarily on the $\Delta \sigma / \Delta P$ evolution along two lines of interest: (1) the middle line of the injection zone, and (2) the interface between the injection zone and upper caprock (Figure 3). 


\subsection{Hydraulic Flow Condition}

The first numerical experiment result presented here is the effect of hydraulic boundary conditions. Figure 4 shows simulation results when the hydraulic boundary of the injection zone (right end) is open for flow. Ratio $\Delta \sigma_{r} / \Delta P$ increases with distance away from the injection well (Figure $4 \mathrm{a}$ and $\mathrm{b}$ ). Note that stresses are transmitted via the deformation of rock skeleton, whereas pore pressure diffuses through pore space (Altmann et al., 2010). Because the propagation of stress does not depend on the intrinsic permeability of a porous medium, change in stress travels faster than change in pore pressure (Rutqvist, 2012). As a result, change in pressure diminishes toward zero faster than change in total stresses, which leads to the ascent in the ratio $\Delta \sigma_{r} / \Delta P$ away from the injection well. As time elapses, a broader area in the injection zone converges to $\Delta \sigma_{r} / \Delta P=\alpha \cdot(1-2 v) /(1-v)$, designated as the long-term limit solution of the homogeneous infinite model (Figure 4a). We also observed that the asymptotic value of $\Delta \sigma_{r} / \Delta P$ is greater at the interface between the injection zone and the upper caprock (called the interface hereafter; line [b] in Figure 3) than it is along the middle of the injection zone (called the middle hereafter; line [a] in Figure 3). Because fluid flow into the caprock is hindered by the latter's low permeability, excess pore pressure at the interface causes more compression to be transmitted to the rock skeleton, which leads to a higher ratio of pore-pressure/stress change $\Delta \sigma / \Delta P$ at the interface than at the middle.

On the other hand, the other ratio, $\Delta \sigma_{z} / \Delta P$, decreases with distance away from the injection well; it even converts from positive (compressive) to negative (tensile) values (Figure 4c). Similar to radial stress, $\Delta \sigma_{z} / \Delta P$ is higher at the interface than at the middle (Figure $4 \mathrm{c}$ and d). Moreover, a broad area at the interface converges to the long-term limit solution of the homogeneous infinite model $\Delta \sigma_{z} / \Delta P \approx(\alpha / 2) \cdot(1-2 v) /(1-v)$, whereas the middle line converges to 
$\Delta \sigma_{z} / \Delta P \approx 0$. Expansion of the pressurized injection zone is partly resisted by the rigidity of overlying caprock (Rutqvist et al., 2007), which also hinders infiltration of pressurized fluid into it. These mechanisms cause the vertical compression at the interface as well as in the lower part of the caprock (Segall and Fitzgerald, 1998; Vilarrasa et al., 2013a), suggesting that neglecting the vertical stress change is valid only for the inside of an injection zone. The spatiotemporal changes of both ratios, $\Delta \sigma_{r} / \Delta P$ and $\Delta \sigma_{\mathrm{z}} / \Delta P$, become trivial beyond $\sim 10$ days of fluid injection and exhibit their rapid convergence to asymptote curves.

Next, we changed the permeability of the injection zone from $k_{I Z}=100 \mathrm{md}$ to $k_{I Z}=10 \mathrm{md}$ to examine its effect on $\Delta \sigma / \Delta P$. Asymptotic values do not seem to be affected by the permeability change of the injection zone. However, $\Delta \sigma / \Delta P$ converges more slowly to its asymptote curve as permeability descends (Figure 5).

We also investigated the effect of the hydraulic boundary condition of the injection zone. Asymptote curves become flat as the boundary condition changes from open to closed (compare Figures 4 and 6). Specifically, the entire area converges to the corresponding long-term limit solutions (i.e., $\Delta \sigma_{r} / \Delta P \approx \alpha \cdot(1-2 v) /(1-v)$ at the middle and $\Delta \sigma_{z} / \Delta P \approx(\alpha / 2) \cdot(1-2 v) /(1-v)$ at the interface) when the hydraulic boundary closes. The no-flow condition permits pore-pressure buildup to accumulate at the boundary in a way similar to how stress incrementally accumulates. As a result, the entire length attains the same value of $\Delta \sigma / \Delta P$ after a certain period of time elapses ( 10 days for this simulation model).

We observed that the asymptotic value of $\Delta \sigma_{r} / \Delta P$ is at its minimum whereas that of $\Delta \sigma_{z} / \Delta P$ is at its maximum near the injection well in all cases (Figures 4-6). In addition, the ratios 
$\Delta \sigma_{r} / \Delta P$ and $\Delta \sigma_{z} / \Delta P$ along the middle of the injection zone are smaller than those at the interface between the injection zone and the upper caprock.

\subsection{Permeability of Caprock}

We conducted a second set of numerical experiments in which the permeability of caprock is changed from $k_{c a p}=1$ nd (almost impermeable) to $k_{c a p}=1 \mu \mathrm{d}$ (permeable to some extent) to investigate how caprock permeability influences the ratio $\Delta \sigma / \Delta P$. It was observed that both ratios $\Delta \sigma_{r} / \Delta P$ and $\Delta \sigma_{z} / \Delta P$ are barely affected at the middle by the change in caprock permeability (Figure $7 \mathrm{a}$ and $\mathrm{c}$ ). However, the asymptote curves of these ratios at the interface shifted downward, closer to curves for the middle of the injection zone (Figure $7 \mathrm{~b}$ and d). This result supports the previous rationale that the hindrance of fluid flow into the caprock contributes to yielding values of $\Delta \sigma / \Delta P$ higher at the interface compared with values inside the injection zone. 


\subsection{Property Contrast: Poisson's Ratio}

In the previous simulations, two parameters-Poisson's ratio and Biot's coefficient, which mainly determine asymptotic values of $\Delta \sigma / \Delta P$-were assigned identically to both injection zone and upper caprock. To find out what would happen if these parameters between the injection zone and upper caprock were different, we conducted two other numerical experiments: in Case I, Poisson's ratio was set at $v_{I Z}=0.15$ for the injection zone and $v_{\text {cap }}=0.3$ for the upper caprock; in Case II, these values were switched between the two layers. These results are compared with two reference cases: in Reference I, Poisson's ratio was set at $v=0.15$ for all layers; in Reference II, it was set at $v=0.30$ for all layers. (Note that Biot's coefficient $\alpha$ was set the same for all layers in this study.)

Case I. At the middle, both ratios $\Delta \sigma_{r} / \Delta P$ and $\Delta \sigma_{z} / \Delta P$ match well with those from Reference I (Figure 8a and c). At the interface, $\Delta \sigma_{z} / \Delta P$ again matches well with the ratio from Reference I (Figure 8d). However, $\Delta \sigma_{r} / \Delta P$ values lie between two curves from References $I$ and II (Figure 8b).

Case II. At the interface, the ratio $\Delta \sigma_{r} / \Delta P$ again falls between the two curves from References $I$ and $I I$ (Figure 8b), the same trend as observed in Case I. Other values, $\Delta \sigma_{z} / \Delta P$ at the interface and $\Delta \sigma_{r} / \Delta P$ and $\Delta \sigma_{z} / \Delta P$ at the middle, agree well with ratios from Reference II (Figures $8 \mathrm{a}, \mathrm{b}$, and d).

These numerical experiments suggest that the radial pore-pressure/stress change ratio $\Delta \sigma_{r} / \Delta P$ at the interface can be approximated to be an average of two reference cases, where Poisson's ratio from either the injection zone or the caprock is assigned identically to both layers. Aside from ratio $\Delta \sigma_{r} / \Delta P$ at the interface, other ratios follow the reference condition, where 
Poisson's ratio of injection zone is set the same at both layers. Refer to Vilarrasa et al. for similar hydromechanical analyses for different material properties (Vilarrasa et al., 2013a).

\section{$\underline{4.4 \text { Hydraulic Barrier }}$}

For the last set of numerical experiments, a hydraulic barrier was inserted into the injection zone at a different distance from the injection well. The hydraulic barrier ran vertically from top to bottom of the injection zone so no fluid could propagate beyond it. Numerical simulation results show that the asymptote curve of $\Delta \sigma_{r} / \Delta P$ moves upward the farther the hydraulic barrier is located from the injection well. The asymptote curve eventually converges to the curve of the condition where the right end of the injection zone is closed (Figures 6a and b,

$9 \mathrm{a}$ and $\mathrm{b})$. The opposite trend is observed for the other ratio, $\Delta \sigma_{z} / \Delta P$ : the asymptote curve shifts downward as the hydraulic barrier is located farther away, and it converges again to the curve of the same condition as above (Figures $6 \mathrm{c}$ and $\mathrm{d}, 9 \mathrm{c}$ and d). This pattern occurs because a greater portion of compression is imparted to the vertical stress as the hydraulic barrier shortens the travel distance for pressurized fluid flow, resulting in smaller $\Delta \sigma_{r} / \Delta P$ and higher $\Delta \sigma_{z} / \Delta P$ values. This observation also supports the theory that stresses redistribute with different ratios if a structural anomaly such as the hydraulic barrier is present inside of the injection zone.

\subsection{Suggestion: Evaluating a Reservoir Stress Path}

It is often necessary to quickly determine whether a current injection rate needs to be lowered after a certain magnitude of pressure buildup. In this regard, we suggest a guideline that semianalytically determines the ratio of pore-pressure/stress changes, which can lead to a more precise evaluation of the reservoir stress path. In the radial direction, we suggest using $\Delta \sigma_{r} / \Delta P=\alpha \cdot(1-2 v) /(1-v)$ for the inside of an injection zone as well as for the interface between the 
injection zone and caprock to update the stress with a given estimate of pore-pressure buildup. In the vertical direction, we recommend adopting $\Delta \sigma_{z} / \Delta P=0$ for the inside of an injection zone and $\Delta \sigma_{z} / \Delta P=(\alpha / 2) \cdot(1-2 v) /(1-v)$ at the interface to update the stress.

If Poisson's ratio between the injection zone and upper caprock is noticeably different, we suggest using $\Delta \sigma / \Delta P$ of the reference condition, where Poisson's ratio of the injection zone is solely assigned to these layers, except $\Delta \sigma_{r} / \Delta P$ at the interface. The ratio $\Delta \sigma_{r} / \Delta P$ at the interface can be approximated to be an average of two reference cases, where Poisson's ratio from either the injection zone or the caprock is solely assigned to these layers.

If a structural geometry is complex (e.g., an impermeable fault exists in an injection zone), we recommend conducting numerical simulations that incorporate the poroelastic effect in advance to determine asymptotic values of $\Delta \sigma_{r} / \Delta P$ and $\Delta \sigma_{z} / \Delta P$, because these values could deviate significantly from the long-term limit solutions of the ideal geometry.

\section{Implications for $\mathrm{CO}_{2}$ Geological Storage: Maximum Sustainable Pressure Limit}

The ratios of pore-pressure/stress change need to be reflected in updating stress fields during fluid injection. In this section, we discuss an analytical approach in which $\Delta \sigma / \Delta P$ is incorporated for determining the maximum sustainable pressure limit.

\section{$\underline{5.1 \text { Failure Criterion and Effective Stress }}$}

Reactivation of preexisting fractures via shear slip (or induced seismicity) determines the maximum sustainable pressure limit because, in most cases, such reactivation occurs prior to shear failures of intact rock and/or tensile fractures (Rutqvist et al., 2007; Rutqvist et al., 2008). Assuming that preexisting fractures may exist at any point with an arbitrary orientation, the 
potential of shear slip can be expressed as a function of the coefficient of internal cohesion $S_{0}$ and the angle of internal fracture friction $\phi$ based on the Coulomb failure criterion (Jaeger et al., 2007):

$$
\left|\tau_{m 2}\right|=\left(\sigma_{m 2}-P_{c}\right) \sin \phi+S_{0} \cos \phi
$$

where $\tau_{\mathrm{m} 2}=\left(\sigma_{1}-\sigma_{3}\right) / 2$ denotes maximum shear stress, $\sigma_{m 2}=\left(\sigma_{1}+\sigma_{3}\right) / 2$ represents mean stress in the two-dimensional principal stress plane, and $P_{c}$ denotes critical pore-pressure required to trigger the shear slip (compression is defined positive). If we assume that cohesion is zero for preexisting fractures, Equation 21 can be expressed in terms of effective principal stresses $\sigma_{l}{ }^{\prime}$ and $\sigma_{3}^{\prime}:$

$$
\sigma_{1}^{\prime}=q_{s l i p} \sigma_{3}^{\prime}
$$

Slope $q_{\text {slip }}$ in Equation 22 is a sole function of friction angle:

$$
q_{\text {slip }}=\left[\left(\tan ^{2} \phi+1\right)^{1 / 2}+\tan \phi\right]^{2}
$$

If we consider $30^{\circ}$ for the friction angle, slope becomes $q_{\text {slip }}=3$.

In traditional approaches, effective stress is assessed simply with the initial total stress $\sigma_{0}$, pore-pressure $P=P_{0^{+}} \Delta P$, and Biot's coefficient as $\sigma^{\prime}=\sigma_{0^{-}} \alpha\left(P_{0^{+}} \Delta P\right)$ (Guéguen and Boutéca, 2004). However, if we consider that the ratio of pore-pressure/stress change $\Delta \sigma / \Delta P$ persists during fluid injection, vertical and horizontal effective stresses $\sigma_{v}^{\prime}$ and $\sigma_{h}^{\prime}$ evolve with pore-pressure buildup as follows:

$$
\sigma_{v}^{\prime}=\sigma_{v 0}+\Delta \sigma_{v}^{P}-\alpha P_{f}=\sigma_{v 0}+\beta_{v} \Delta P-\alpha\left(P_{0}+\Delta P\right)
$$




$$
\sigma_{h}^{\prime}=\sigma_{h 0}+\Delta \sigma_{h}^{P}-\alpha P_{f}=\sigma_{h 0}+\beta_{h} \Delta P-\alpha\left(P_{0}+\Delta P\right)
$$

where $\beta_{v}=\Delta \sigma_{v} / \Delta P$ denotes the ratio of change in total vertical stress to change in pore pressure and $\beta_{h}=\Delta \sigma_{h} / \Delta P$ denotes the ratio of change in total horizontal stress to change in pore pressure. In the following section, we examine how the pore-pressure/stress coupling affects effective stresses and how the maximum sustainable pressure limit can be evaluated on the basis of Equations 24 and 25 .

\subsection{Maximum Pressure Limit}

First, we investigate a hypothetical case in which a storage reservoir belongs to an extensional stress regime (i.e., a normal-faulting stress regime). If we consider the reservoir to be located $1 \mathrm{~km}$ below the surface, with an average density of porous media $\rho_{t}=2650 \mathrm{~kg} / \mathrm{m}^{3}$, water density $\rho_{w}=1000 \mathrm{~kg} / \mathrm{m}^{3}$, and initial total stress ratio $K=\sigma_{h 0} / \sigma_{v 0}=0.7$, then the initial stress state is as follows: total vertical stress $\sigma_{v 0}=26 \mathrm{MPa}$, total horizontal stress $\sigma_{h 0}=18.2 \mathrm{MPa}$, and initial pore pressure $P_{0}=9.8 \mathrm{MPa}$. We evaluate maximum allowable increase in pore pressure $\Delta P_{\max }$ before triggering the reactivation of preexisting fractures for the following four scenarios: (1) Total stresses remain constant (traditional approach). (2) Both horizontal and vertical stresses change with same ratio $\beta_{h}=\beta_{v}=0.5$ (can be used as an analogy to a strike-slip faulting stress regime). (3) Only horizontal stress couples with pore-pressure buildup $\beta_{h}=0.66$ (from $\alpha \cdot(1-2 v) /(1-v)$ where $\alpha=1$ and $v=0.25$; prevalent method for a simplified-poroelastic analytical calculation (Chiaramonte et al., 2008; Vidal-Gilbert et al., 2010; Zoback and Zinke, 2002). (4) Horizontal and vertical stresses increase with different ratios $\beta_{h}=0.66$ and $\beta_{v}=0.33$ (from $(\alpha / 2) \cdot(1-2 v) /(1-v)$; in accordance with this study). 
Figure 10 illustrates anticipated stress paths in the $\sigma_{v^{\prime}}^{\prime} \sigma_{h}^{\prime}$ space and corresponding Mohr circles in the $\tau$ - $\sigma^{\prime}$ space for these four scenarios. The traditional approach (scenario 1) yields the maximum sustainable pressure limit $\Delta P_{\text {max }} \approx 4.4 \mathrm{MPa}$ (Figure 10a), while the limit value doubles to $\Delta P_{\max } \approx 8.7 \mathrm{MPa}$ for scenario 2 (Figure $10 \mathrm{~b}$ ). The slope of the stress path $\Delta \sigma^{\prime}{ }_{v} / \Delta \sigma_{h}^{\prime}$ is identical for these two scenarios. The maximum sustainable pressure limit ascends to $\Delta P_{\text {max }} \approx 15 \mathrm{MPa}$ in scenario 3 (Figure 10c). Noticeably, the stress regime transitions during the pore-pressure buildup in a way that horizontal stress surpasses vertical stress $\left(\sigma_{h}>\sigma_{v}\right)$. This event occurs because only $\Delta \sigma_{h} / \Delta P$ is reflected; as a result, the stress path approaches the other failure criterion $\sigma_{h}^{\prime}=q_{s l i p} \cdot \sigma_{v}^{\prime}$ instead of $\sigma_{v}^{\prime}=q_{s l i p} \cdot \sigma_{h}^{\prime}$. Lastly, scenario 4 yields the maximum sustainable pressure limit $\Delta P_{\text {max }} \approx 22.5 \mathrm{MPa}$; vertical and horizontal stresses become comparable as they approach the shear slip line in this scenario (Figure 10d). Note also that Mohr circles shrink and shift leftward toward the failure criterion in scenarios 3 and 4 as pore pressure increases under an extensional stress regime.

Next, we examine an opposite case in which a storage reservoir belongs to a compressional stress regime (i.e., a reverse-faulting stress regime) with the initial total stress ratio $K=\sigma_{h 0} / \sigma_{v 0}=1.5$; corresponding horizontal stress is $\sigma_{h 0}=39 \mathrm{MPa}$ (other values are the same as in the previous analysis). The stress path during pore-pressure buildup and the maximum sustainable pressure limit for each scenario is summarized in Figure 11. The stress regime does not transition for all of these scenarios; only the slope of stress path $\Delta \sigma^{\prime}{ }_{v} / \Delta \sigma_{h}^{\prime}$ differs. Again, scenario 2 yields the maximum sustainable pressure limit, twice that of the traditional approach, $\Delta P_{\text {max }} \approx 19.2 \mathrm{MPa}=2 \times 9.6 \mathrm{MPa}$ (Figure $11 \mathrm{a}$ and $\mathrm{b}$ ), with an identical stress path gradient. Interestingly, scenario 3 results in the maximum sustainable pressure limit, smaller than that from the traditional approach, $\Delta P_{\max } \approx 7.5 \mathrm{MPa}<9.6 \mathrm{MPa}$ (Figure $11 \mathrm{a}$ and c). Scenario 4 yields the 
maximum sustainable pressure limit $\Delta P_{\max } \approx 11.4 \mathrm{MPa}$, which is slightly higher than that from the traditional approach by $\sim 2 \mathrm{MPa}$ (Figure 11d). Contrary to the extensional stress regime, Mohr circles enlarge in scenarios 3 and 4 as pore pressure increases (Figure 11c and d).

These examples illustrate that the discrepancy in the maximum sustainable pressure limit could be substantial, depending on the consideration of stress evolution. Therefore, we emphasize that initial stress state, material properties, and structural geometry conditions combine to incur site-specific ratios of pore-pressure/stress changes; thus, the maximum sustainable pressure limit should be determined accordingly.

\section{$\underline{5.3 \text { Application }}$}

We applied the suggested guideline to the case study, where potential for a shear slip was numerically evaluated on the basis of sequential coupling between multiphase fluid flow and geomechanics (TOUGH-FLAC; (Rutqvist et al., 2007)). Rutqvist et al. (2007) simulated $\mathrm{CO}_{2}$ injection into a storage aquifer (1.5 km depth) overlain by low-permeability caprock (Poisson's ratio is $v=0.25$ and Biot's coefficient is $\alpha=1$; other parameters are listed in Table 1 in (Rutqvist et al., 2007)). The numerical simulation yielded $\Delta P_{\max }=13.3 \mathrm{MPa}$ for an extensional stress regime $\left(\sigma_{h 0} / \sigma_{v 0}=0.7\right)$, whereas the traditional approach and simplified poroelastic analysis $\left(\beta_{h}=\alpha(1-\right.$ $2 v) /(1-v)=0.67$ and $\left.\beta_{v}=0\right)$ yielded $\Delta P_{\max }=3.3 \mathrm{MPa}$ and $\Delta P_{\max }=48.3 \mathrm{MPa}$, respectively. The numerical simulation led to an observation that the traditional approach underestimates the pressure limit, whereas the simplified poroelastic analysis grossly overestimates the pressure limit for an extensional stress regime (Rutqvist et al., 2007). However, if we apply $\beta_{h}=0.66$ and $\beta_{v}=0.33$ for the interface between the injection zone and upper caprock, based on this study's observations when $v=0.25$ and $\alpha=1$, the maximum pressure limit is calculated as 
$\Delta P_{\text {max }} \approx 13.5 \mathrm{MPa}$, which shows good agreement with the sequentially coupled numerical simulation result.

We also compared results for the reservoir in a compressional stress regime $\left(\sigma_{h 0} / \sigma_{v 0}=1.5\right)$, with the other conditions the same. The sequentially coupled numerical simulation yielded $\Delta P_{\max }=9.3 \mathrm{MPa}$, whereas the traditional approach and simplified poroelastic analysis resulted in $\Delta P_{\text {max }}=10.3 \mathrm{MPa}$ and $\Delta P_{\max }=12.3 \mathrm{MPa}$, respectively (Rutqvist et al., 2007). If we apply $\beta_{h}=0.66$ and $\beta_{v}=0.33$, the maximum pressure limit is calculated as $\Delta P_{\max } \approx 11.4 \mathrm{MPa}$. Even though discrepancies between the other analytical computations (traditional and simplified poroelastic) and the numerical simulation method are not significant for the compressional stress regime, the proposed guideline once again leads to a good match with the sequentially coupled numerical simulation.

\section{Conclusions}

Predicting an increase in pore pressure and ensuing changes in the state of stresses during and after fluid injection is critical for the success of $\mathrm{CO}_{2}$ geologic storage. To examine effects of material properties, boundary conditions, and structural geometries, we conducted numerical experiments to investigate the spatiotemporal evolution of the ratio of change in total stress to change in pore pressure $\Delta \sigma / \Delta P$ during fluid injection under various conditions. Salient observations are as follows:

- The ratio of change in radial stress to that in pore pressure $\Delta \sigma_{r} / \Delta P$ escalates with distance away from the injection well. As the fluid injection persists, a broad area in the injection zone converges to $\Delta \sigma_{r} / \Delta P \approx \alpha \cdot(1-2 v) /(1-v)$. Moreover, impermeable upper caprock causes the 
asymptotic value of $\Delta \sigma_{r} / \Delta P$ at the interface between the injection zone and the caprock to be larger than that at the middle of the injection zone by $0.1 \sim 0.15$.

- The 1:1 (horizontal:vertical) model size yields the identical result of $\Delta \sigma_{r} / \Delta P \approx \alpha \cdot(1-2 v) /(1-v)$ inside the injection zone compared to a theoretical thin \& laterally extensive reservoir condition.

- The ratio of change in vertical stress to that in pore pressure $\Delta \sigma_{z} / \Delta P$ not only decreases with distance away from the injection well but also converts from positive (compression) to negative (tension). A broad area at the interface converges to $\Delta \sigma_{z} / \Delta P \approx(\alpha / 2) \cdot(1-2 v) /(1-v)$, while the middle line converges to $\Delta \sigma_{z} / \Delta P \approx 0$. Therefore, regarding the vertical pore-pressure/stress change ratio as $\Delta \sigma_{z} / \Delta P=0$ is valid only for the inside of the injection zone.

- The asymptote curves for $\Delta \sigma / \Delta P$ eventually become flat when the hydraulic boundary of the injection zone is closed.

- Two parameters, Biot's coefficient $\alpha$ and Poisson's ratio $v$, determine asymptotic values of $\Delta \sigma / \Delta P$, whereas the Boltzmann variable $\xi=r /(c \cdot t)^{1 / 2}$ influences the spatiotemporal evolution of $\Delta \sigma / \Delta P$ en route to its asymptote curve.

- If Poisson's ratio is different between an injection zone $\left(v_{I Z}\right)$ and upper caprock $\left(v_{c a p}\right), \Delta \sigma_{r} / \Delta P$ at the interface falls between curves resulted from the two reference cases, where either $v_{I Z}$ or $v_{c a p}$ is solely assigned to these layers. Other ratios follow curves from the reference case, where $v_{I Z}$ is solely assigned to both injection zone and caprock.

- If a hydraulic barrier, such as an impermeable fault, exists near the injection well, it alters how pore-pressure buildup imparts compression to the stress components. Numerical simulations help 
better capture a complex structural geometry condition. In Section 4.5, we suggest a firsthand guideline to decide the pore-pressure/stress change ratios.

- We suggest incorporating the ratios of pore-pressure/stress changes into an analytic calculation when evaluating stress paths and maximum sustainable pressure limits. While the traditional approach and the simplified poroelastic analysis would underestimate or overestimate the

pressure limit, respectively, accurate reflection of the pore-pressure/stress change ratios can lead to a more reliable evaluation of the maximum sustainable pressure limit.

\section{Acknowledgments}

This work was funded by the Gulf Coast Carbon Center at the Bureau of Economic Geology (BEG) and the U.S. Department of Energy, NETL, under contract numbers DEFE0009301 and DE-FC26-05NT42590. Thanks to Stephanie Jones for editing, and to Susan D. Hovorka and J.-P. Nicot for reviewing this manuscript. Publication authorized by the Director, Bureau of Economic Geology, Jackson School of Geosciences, The University of Texas at Austin.

\section{References}

Addis, M.A., 1997. The stress-depletion response of reservoirs, SPE Annual Technical Conference, pp. $55-65$.

Alfi, M., Hosseini, S.A.,2016. Integration of reservoir simulation, history matching, and 4D seismic for $\mathrm{CO}_{2}$-EOR and storage at Cranfield, Mississippi, USA. Fuel, 175, 116-128.

Altmann, J.B., Müller, T.M., Müller, B.I., Tingay, M.R. and Heidbach, O., 2010. Poroelastic contribution to the reservoir stress path. International Journal of Rock Mechanics and Mining Sciences, 47(7): 11041113.

Biot, M.A., 1941. General theory of three-dimensional consolidation. Journal of Applied Physics, 12(2): 155-164. 
Biot, M.A., 1962. Mechanics of deformation and acoustic propagation in porous media. Journal of Applied Physics, 33(4): 1482-1498.

Chiaramonte, L., Zoback, M.D., Friedmann, J. and Stamp, V., 2008. Seal integrity and feasibility of $\mathrm{CO}_{2}$ sequestration in the Teapot Dome EOR pilot: geomechanical site characterization. Environmental Geology, 54(8): 1667-1675.

Cleary, M.P., 1977. Fundamental solutions for a fluid-saturated porous solid. International Journal of Solids and Structures, 13(9): 785-806.

COMSOL, 2012. 4.3 User's Guide. COMSOL Multiphysics.

De Simone, S., Vilarrasa, V., Carrera, J., Alcolea, A. and Meier, P., 2013. Thermal coupling may control mechanical stability of geothermal reservoirs during cold water injection. Physics and Chemistry of the Earth, Parts A/B/C, 64: 117-126.

Detournay, E., Cheng, A.-D., Roegiers, J.-C. and McLennan, J., 1989. Poroelasticity considerations in In Situ stress determination by hydraulic fracturing, International Journal of Rock Mechanics and Mining Sciences \& Geomechanics Abstracts. Elsevier, pp. 507-513.

Ferronato, M., Gambolati, G., Janna, C. and Teatini, P., 2008. Numerical modelling of regional faults in land subsidence prediction above gas/oil reservoirs. International Journal for Numerical and Analytical Methods in Geomechanics, 32(6): 633-657.

Goodarzi, S., Settari, A., Zoback, M.D. and Keith, D., 2010. Thermal aspects of geomechanics and induced fracturing in $\mathrm{CO}_{2}$ injection with application to $\mathrm{CO}_{2}$ sequestration in Ohio River Valley, SPE International Conference on $\mathrm{CO}_{2}$ Capture Storage and Utilization. Society of Petroleum Engineers, pp. SPE 139706.

Guéguen, Y. and Boutéca, M., 2004. Mechanics of fluid saturated rocks. Academic Press.

Hillis, R.R., 2000. Pore pressure/stress coupling and its implications for seismicity. Exploration Geophysics-Australia-, 31(1/2): 448-454.

Hillis, R.R., 2001. Coupled changes in pore pressure and stress in oil fields and sedimentary basins. Petroleum Geoscience, 7(4): 419-425.

Hosseini, S.A., Alfi, M., 2015. Time-lapse application of pressure transient analysis for monitoring compressible fluid leakage. Greenhouse Gases: Science and Technology, 6(3), 352-369.

Hosseini, S.A. and Nicot, J.-P., 2012. Scoping analysis of brine extraction/re-injection for enhanced $\mathrm{CO}_{2}$ storage. Greenhouse Gases: Science and Technology, 2(3): 172-184.

IPCC, 2005. IPCC special report on carbon dioxide capture and storage. 052186643X, Cambridge University Press, Cambridge, United Kingdom and New York, USA.

Jaeger, J., Cook, N. and Zimmerman, R., 2007. Fundamentals of rock mechanics. Wiley-Blackwell.

Kim, S. and Hosseini, S., 2014. Geological $\mathrm{CO}_{2}$ storage: Incorporation of pore-pressure/stress coupling and thermal effects to determine maximum sustainable pressure limit. Energy Procedia, 63: 3563-3567. 
Kim, S. and Hosseini, S., 2015. Hydro-thermo-mechanical analysis during injection of cold fluid into a geologic formation. International Journal of Rock Mechanics and Mining Sciences, 77: 220-236.

Kim, S. and Santamarina, J.C., 2013. $\mathrm{CO}_{2}$ breakthrough and leak-sealing - Experiments on shale and cement. International Journal of Greenhouse Gas Control, 19: 471-477.

Kim, S. and Santamarina, J.C., 2014. Engineered $\mathrm{CO}_{2}$ injection: The use of surfactants for enhanced sweep efficiency. International Journal of Greenhouse Gas Control, 20: 324-332.

Neuzil, C., 2003. Hydromechanical coupling in geologic processes. Hydrogeology Journal, 11(1): 41-83.

Okwen, R.T., Stewart, M.T. and Cunningham, J.A., 2011. Temporal variations in near-wellbore pressures during $\mathrm{CO}_{2}$ injection in saline aquifers. International Journal of Greenhouse Gas Control, 5(5): 11401148 .

Preisig, M. and Prévost, J.H., 2011. Coupled multi-phase thermo-poromechanical effects. Case study: $\mathrm{CO}_{2}$ injection at In Salah, Algeria. International Journal of Greenhouse Gas Control, 5(4): 1055-1064.

Rudnicki, J.W., 1986. Fluid mass sources and point forces in linear elastic diffusive solids. Mechanics of Materials, 5(4): 383-393.

Rutqvist, J., 2012. The geomechanics of $\mathrm{CO}_{2}$ storage in deep sedimentary formations. Geotechnical and Geological Engineering, 30(3): 525-551.

Rutqvist, J., Birkholzer, J., Cappa, F. and Tsang, C.F., 2007. Estimating maximum sustainable injection pressure during geological sequestration of $\mathrm{CO}_{2}$ using coupled fluid flow and geomechanical fault-slip analysis. Energy Conversion and Management, 48(6): 1798-1807.

Rutqvist, J., Birkholzer, J. and Tsang, C.F., 2008. Coupled reservoir-geomechanical analysis of the potential for tensile and shear failure associated with $\mathrm{CO}_{2}$ injection in multilayered reservoir-caprock systems. International Journal of Rock Mechanics and Mining Sciences, 45(2): 132-143.

Safari, M.R., Trevor, O., Queena, C., Hamed, C., Blair, N., Uno, M. and Hawkes, C., 2013. Effects of depletion/injection induced stress changes on natural fracture reactivation, 47th US Rock Mechanics/Geomechanics Symposium. American Rock Mechanics Association, San Francisco, CA, USA, pp. ARMA 13-395.

Schoenball, M., Müller, T., Müller, B. and Heidbach, O., 2010. Fluid-induced microseismicity in prestressed rock masses. Geophysical Journal International, 180(2): 813-819.

Segall, P. and Fitzgerald, S.D., 1998. A note on induced stress changes in hydrocarbon and geothermal reservoirs. Tectonophysics, 289(1): 117-128.

Selvadurai, A., 2009. Heave of a surficial rock layer due to pressures generated by injected fluids. Geophysical Research Letters, 36(14): L14302.

Shakiba, M., Hosseini, S.A., 2016. Detection and characterization of $\mathrm{CO}_{2}$ leakage by multi-well pulse testing and diffusivity tomography maps. International Journal of Greenhouse Gas Control, 54, 15-28.

Socolow, R.H. and Pacala, S.W., 2006. A plan to keep carbon in check. Scientific American, 295(3): 5057. 
Stauffer, P.H., Keating, G.N., Middleton, R.S., Viswanathan, H.S., Berchtold, K.A., Singh, R.P., Pawar, R.J. and Mancino, A., 2011. Greening coal: breakthroughs and challenges in carbon capture and storage. Environmental Science \& Technology, 45(20): 8597-8604.

Streit, J.E. and Hillis, R.R., 2004. Estimating fault stability and sustainable fluid pressures for underground storage of $\mathrm{CO}_{2}$ in porous rock. Energy, 29(9-10): 1445-1456.

Verruijt, A., 1969. Elastic storage of aquifers. Flow Through Porous Media: 331-376.

Vidal-Gilbert, S., Tenthorey, E., Dewhurst, D., Ennis-King, J., Van Ruth, P. and Hillis, R., 2010. Geomechanical analysis of the Naylor Field, Otway Basin, Australia: Implications for $\mathrm{CO}_{2}$ injection and storage. International Journal of Greenhouse Gas Control, 4(5): 827-839.

Vilarrasa, V., Carrera, J. and Olivella, S., 2013a. Hydromechanical characterization of $\mathrm{CO}_{2}$ injection sites. International Journal of Greenhouse Gas Control, 19: 665-677.

Vilarrasa, V., Olivella, S., Carrera, J. and Rutqvist, J., 2014. Long term impacts of cold $\mathrm{CO}_{2}$ injection on the caprock integrity. International Journal of Greenhouse Gas Control, 24: 1-13.

Vilarrasa, V., Silva, O., Carrera, J. and Olivella, S., 2013b. Liquid $\mathrm{CO}_{2}$ injection for geological storage in deep saline aquifers. International Journal of Greenhouse Gas Control, 14: 84-96.

Wang, H.F., 2000. Theory of Linear Poroelasticity: With Applications to Geomechanics and Hydrogeologoy. Princeton University Press, New Jersey.

Zoback, M.D. and Zinke, J.C., 2002. Production-induced normal faulting in the Valhall and Ekofisk oil fields. Pure and Applied Geophysics, 159: 403-420. 


\section{Figure Captions}

Fig. 1 Examples of change in state of stresses during fluid extraction/injection. (a) and (b): traditional approach; (c) and (d): poroelastic approach. Note: This illustration is for normal-faulting stress regime $\left(\sigma_{h}<\sigma_{H}<\sigma_{v}\right)$; ratio of pore-pressure/stress change is greater for horizontal stress $\left(\Delta \sigma_{v} / \Delta P<\Delta \sigma_{h} / \Delta P\right)$. After Hillis (2001).

Fig. 2 Verification of the numerical simulation method: comparison between results from numerical simulation and analytical solution. (a) Ratio of change in radial stress to change in pore pressure $\Delta \sigma_{r} / \Delta P$, and (b) ratio of change in vertical stress to change in pore pressure $\Delta \sigma_{z} / \Delta P$. Note: Solid line represents numerical simulation results, and dashed line represents analytical solution. Injection point located $5 \mathrm{~km}$ deep from surface for axisymmetric reservoir model. Used material properties: injection rate $Q=20 \mathrm{~kg} / \mathrm{s}$, fluid density $\rho_{f}=1000 \mathrm{~kg} / \mathrm{m}^{3}$, porosity $\varphi=0.167$, diffusivity $c=0.082 \mathrm{~m}^{2} / \mathrm{s}$, Lame parameters $\lambda_{u}=13.4 \mathrm{GPa}, \lambda=8.3 \mathrm{GPa}, G=5.5 \mathrm{GPa}$, Biot's coefficient $\alpha=0.7$. Injection period=164 days (Altmann et al., 2010).

Fig. 3 Simulation model for numerical experiments in this study: geometry, lines of interest (center line of injection zone and interface between injection zone and upper caprock), and illustration of hydraulic barrier (activated at several realizations).

Fig. 4 Spatiotemporal evolution of pore-pressure/stress change ratios when hydraulic boundary of injection zone is open. (a) $\Delta \sigma_{r} / \Delta P$ at middle of injection zone, (b) $\Delta \sigma_{r} / \Delta P$ at interface between the injection zone and upper caprock, (c) $\Delta \sigma_{z} / \Delta P$ at middle, (d) $\Delta \sigma_{z} / \Delta P$ at interface, and (e) $\Delta P$ in the injection zone. Note: Blue line represents after time $t=1$ day, green line represents after $t=10$ days, and red line represents after $t=1$ year. $v=0.3, \varphi=0.25, \alpha=1$ for all layers, permeability of injection zone is $k_{I Z}=100 \mathrm{md}$, and permeability of upper caprock is $k_{c a p}=1$ nd. Other parameters as listed in Table 1.

Fig. 5 Spatiotemporal evolution of pore-pressure/stress change ratios when permeability of injection zone changes to $k_{I Z}=10 \mathrm{md}$ for open-end boundary condition. (a) $\Delta \sigma_{r} / \Delta P$ at middle, (b) $\Delta \sigma_{r} / \Delta P$ at interface, (c) $\Delta \sigma_{z} / \Delta P$ at middle, (d) $\Delta \sigma_{z} / \Delta P$ at interface, and (e) $\Delta P$ in injection zone. $v=0.3, \varphi=0.25, \alpha=1$ for all layers, and $k_{c a p}=1$ nd. Other parameters as listed in Table 1. 
Fig. 6 Spatiotemporal evolution of pore-pressure/stress change ratios when hydraulic boundary of injection zone is closed. (a) $\Delta \sigma_{r} / \Delta P$ at middle, (b) $\Delta \sigma_{r} / \Delta P$ at interface, (c) $\Delta \sigma_{z} / \Delta P$ at middle, (d) $\Delta \sigma_{z} / \Delta P$ at interface, and (e) $\Delta P$ in injection zone. $v=0.3, \varphi=0.25$, $\alpha=1$ for all layers, $k_{I Z}=100 \mathrm{md}$, and $k_{c a p}=1 \mathrm{nd}$. Other parameters as listed in Table 1.

Fig. 7 Spatial evolution of pore-pressure/stress change ratios when permeability of caprock $k_{\text {cap }}$ varies. (a) $\Delta \sigma_{r} / \Delta P$ at middle, (b) $\Delta \sigma_{r} / \Delta P$ at interface, (c) $\Delta \sigma_{z} / \Delta P$ at middle, and (d) $\Delta \sigma_{z} / \Delta P$ at interface. Note: Solid line represents when $k_{c a p}=1 \mathrm{nd}$, and dashed line represents when $k_{c a p}=1 \mu \mathrm{d}$. $v=0.3, \varphi=0.25, \alpha=1$ for all layers, and $k_{I Z}=100 \mathrm{md}$. Other parameters as listed in Table 1 . Total simulation time $t_{\text {simul }}=1$ year.

Fig. 8 Spatial evolution of pore-pressure/stress change ratios when Poisson's ratio differs between injection zone and upper caprock. (a) $\Delta \sigma_{r} / \Delta P$ at middle, (b) $\Delta \sigma_{r} / \Delta P$ at interface, (c) $\Delta \sigma_{z} / \Delta P$ at middle, and (d) $\Delta \sigma_{z} / \Delta P$ at interface. Note: Black solid line represents Case I while red solid line represents Case II. Dot-dashed line represents Reference I, and dashed line represents Reference II. $\varphi=0.25, \alpha=1$ for all layers, $k_{I Z}=100 \mathrm{md}$, and $k_{c a p}=1 \mathrm{nd}$. Other parameters as listed in Table 1 . Total simulation time $t_{\text {simul }}=1$ year.

Fig. 9 Spatial evolution of pore-pressure/stress change ratios when hydraulic barrier exists in injection zone. (a) $\Delta \sigma_{r} / \Delta P$ at middle, (b) $\Delta \sigma_{r} / \Delta P$ at interface, (c) $\Delta \sigma_{z} / \Delta P$ at middle, and (d) $\Delta \sigma_{z} / \Delta P$ at interface. Note: Solid line represents when location of hydraulic barrier is $100 \mathrm{~m}$ away from injection well; dot-dashed line represents hydraulic barrier 500 m away; longer dashed line represents hydraulic barrier 1000 m away; and shorter dashed line represents long-term limit solution of homogeneous infinite model. $v=0.3, \varphi=0.25, \alpha=1$ for all layers, $k_{I Z}=100 \mathrm{md}$, and $k_{c a p}=1 \mathrm{nd}$. Other parameters as listed in Table 1 . Total simulation time $t_{\text {simul }}=1$ year.

Fig. 10 Stress paths in effective stress $\sigma_{v^{-}}^{\prime} \sigma_{h}^{\prime}$ space and corresponding Mohr circles with Coulomb failure criterion in the $\tau$ - $\sigma^{\prime}$ space for a storage reservoir of $K=\sigma_{h 0} / \sigma_{v 0}=0.7$. (a) Traditional approach, (b) when $\beta_{h}=\beta_{v}=0.5$, (c) when $\beta_{h}=0.66, \beta_{v}=0$, and (d) when $\beta_{h}=0.66, \beta_{v}=0.33$. Note: Mohr circle $A$ represents initial stress state; $B$ denotes stress state after pore pressure increases by $\Delta P=4.4 \mathrm{MPa}$, maximum limit for traditional 
approach; and $C$ describes stress state at moment of shear slip after considering ratios of pore-pressure/stress changes differently in each scenario.

Fig. 11 Stress paths in effective stress space and corresponding Mohr circles for a storage reservoir of $K=\sigma_{h o} / \sigma_{v 0}=1.5$. (a) Traditional approach, (b) when $\beta_{h}=\beta_{v}=0.5$, (c) when $\beta_{h}=0.66, \beta_{v}=0$, and (d) when $\beta_{h}=0.66, \beta_{v}=0.33$. Note: Mohr circle $A$ represents initial stress state; $B$ denotes stress state after $\Delta P=9.6 \mathrm{MPa}$, maximum limit for traditional approach; and $C$ describes stress state at moment of shear slip after considering ratios of pore-pressure/stress changes differently in each scenario. 
Table 1 Input parameters for numerical simulations

\begin{tabular}{lccc} 
Property & Symbol & \multicolumn{2}{c}{ Value } \\
\cline { 3 - 4 } & & Injection zone & Confining layers \\
\hline Young's modulus & $E$ & $30 \mathrm{GPa}$ & $30 \mathrm{GPa}$ \\
Poisson's ratio & $v$ & $0.05 \sim 0.4$ & $0.05 \sim 0.4$ \\
Dry bulk density & $\rho_{d}$ & $2250 \mathrm{~kg} / \mathrm{m}^{3}$ & $2250 \mathrm{~kg} / \mathrm{m}^{3}$ \\
Porosity & $\varphi$ & $0.1 \sim 0.4$ & $0.1 \sim 0.4$ \\
Biot's coefficient & $\alpha$ & $0.8 \sim 1$ & $0.8 \sim 1$ \\
Bulk modulus of fluid & $K_{f}$ & $2.2 \mathrm{GPa}$ & $2.2 \mathrm{GPa}$ \\
Density of fluid & $\rho_{f}$ & $1000 \mathrm{~kg} / \mathrm{m}^{3}$ & $1000 \mathrm{~kg} / \mathrm{m}^{3}$ \\
Viscosity of fluid & $\eta$ & $0.001 \mathrm{~Pa} \cdot \mathrm{s}$ & $0.001 \mathrm{~Pa} \cdot \mathrm{s}$ \\
Permeability & $k$ & $10 \mathrm{md} \mathrm{or} 100 \mathrm{md}$ & $1 \mu \mathrm{d}$ or $1 \mathrm{nd}$ \\
Injection rate & $Q$ & \multicolumn{2}{c}{$1 \mathrm{~kg} / \mathrm{s}$} \\
Radius of injection well & $r_{w}$ & \multicolumn{2}{c}{$0.1 \mathrm{~m}$} \\
Thickness of injection zone & $T_{I Z}$ & \multicolumn{2}{c}{$100 \mathrm{~m}$} \\
Depth to top of injection zone & $D_{I Z}$ & \multicolumn{2}{c}{$1000 \mathrm{~m}$} \\
Simulation time & $t_{\text {simul }}$ & $365 \mathrm{days}(1 \mathrm{year})$
\end{tabular}


(a) Fluid Extraction

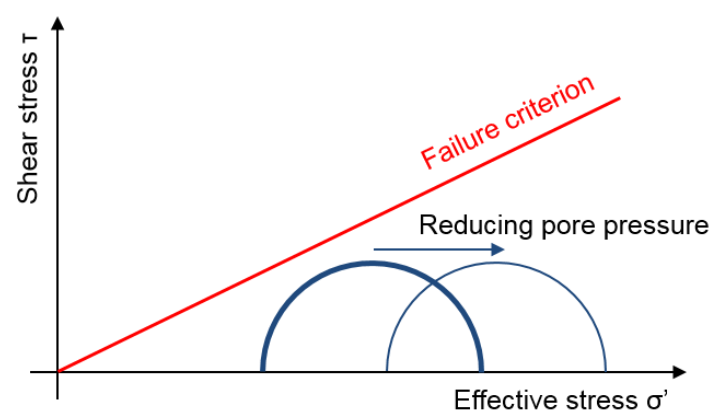

(c) Fluid Extraction - Pore pressure/stress coupling

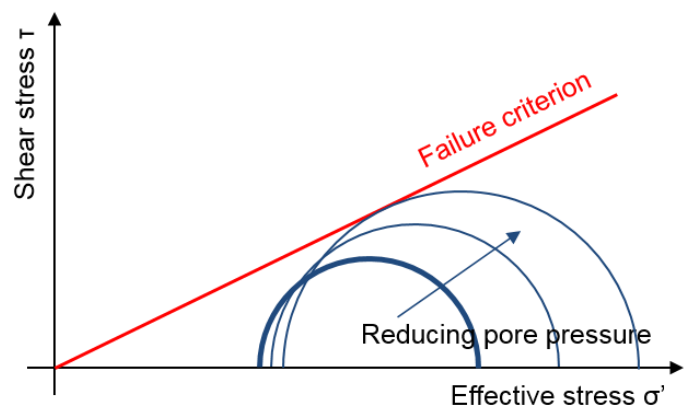

(b) Fluid Injection

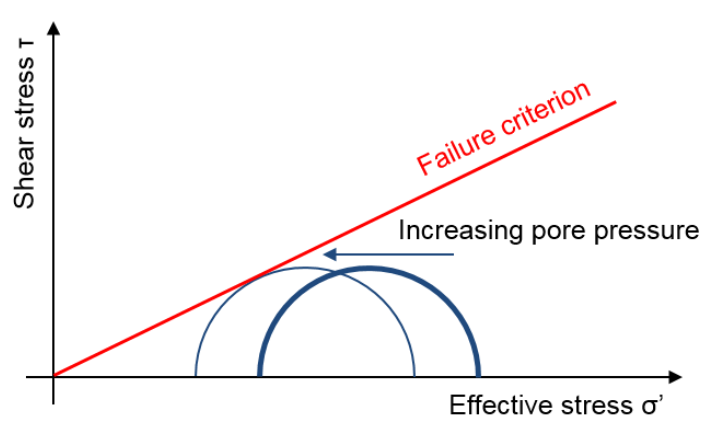

(d) Fluid Injection - Pore pressure/stress coupling

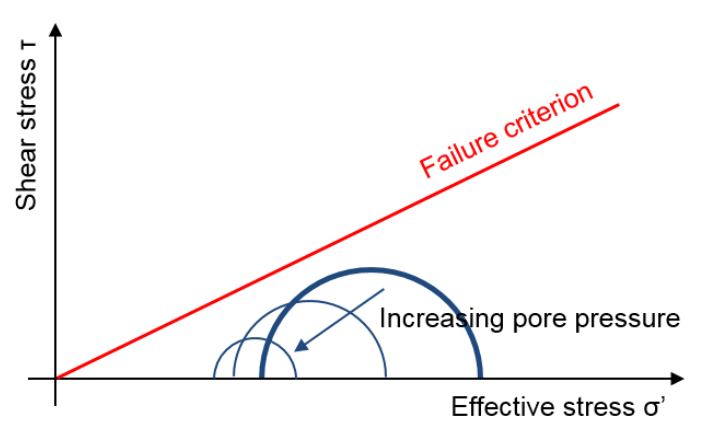

Fig. 1 Examples of change in state of stresses during fluid extraction/injection. (a) and (b): traditional approach; (c) and (d): poroelastic approach. Note: This illustration is for normal-faulting stress regime $\left(\sigma_{h}<\sigma_{H}<\sigma_{v}\right)$; ratio of pore-pressure/stress change is greater for horizontal stress $\left(\Delta \sigma_{v} / \Delta P<\Delta \sigma_{h} / \Delta P\right)$. After Hillis (2001). 
(a)

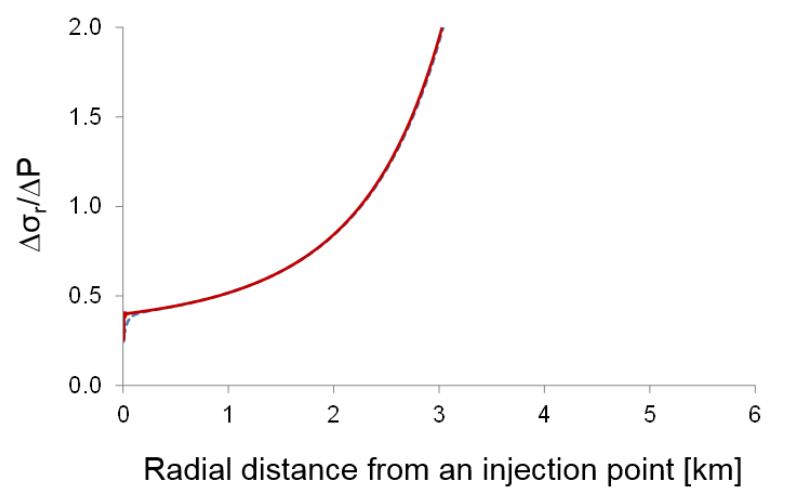

(b)

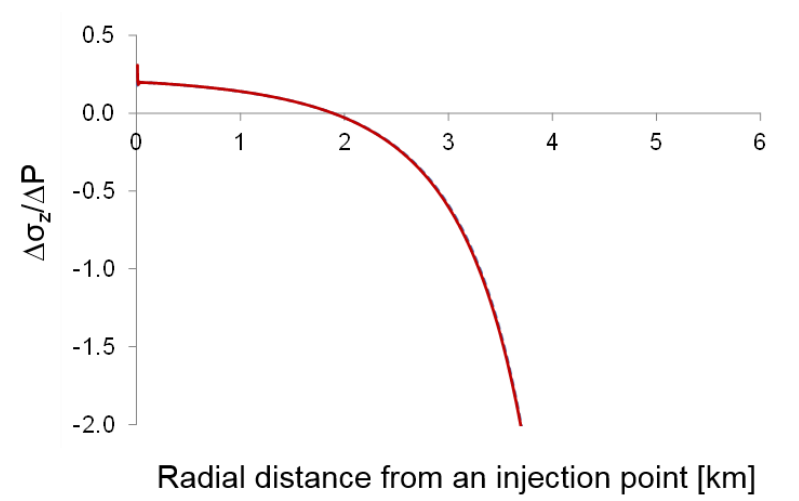

Fig. 2 Verification of numerical simulation method: comparison between results from numerical simulation and analytical solution. (a) Ratio of change in radial stress to change in pore pressure $\Delta \sigma_{r} / \Delta P$, and (b) ratio of change in vertical stress to change in pore pressure $\Delta \sigma_{z} / \Delta P$. Note: Solid line represents numerical simulation results, and dashed line represents analytical solution. Injection point located $5 \mathrm{~km}$ deep from surface for axisymmetric reservoir model. Used material properties: injection rate $Q=20 \mathrm{~kg} / \mathrm{s}$, fluid density $\rho_{f}=1000 \mathrm{~kg} / \mathrm{m}^{3}$, porosity $\varphi=0.167$, diffusivity $c=0.082 \mathrm{~m}^{2} / \mathrm{s}$, Lame parameters $\lambda_{u}=13.4 \mathrm{GPa}, \lambda=8.3 \mathrm{GPa}, G=5.5 \mathrm{GPa}$, Biot's coefficient $\alpha=0.7$. Injection period=164days (Altmann et al., 2010). 


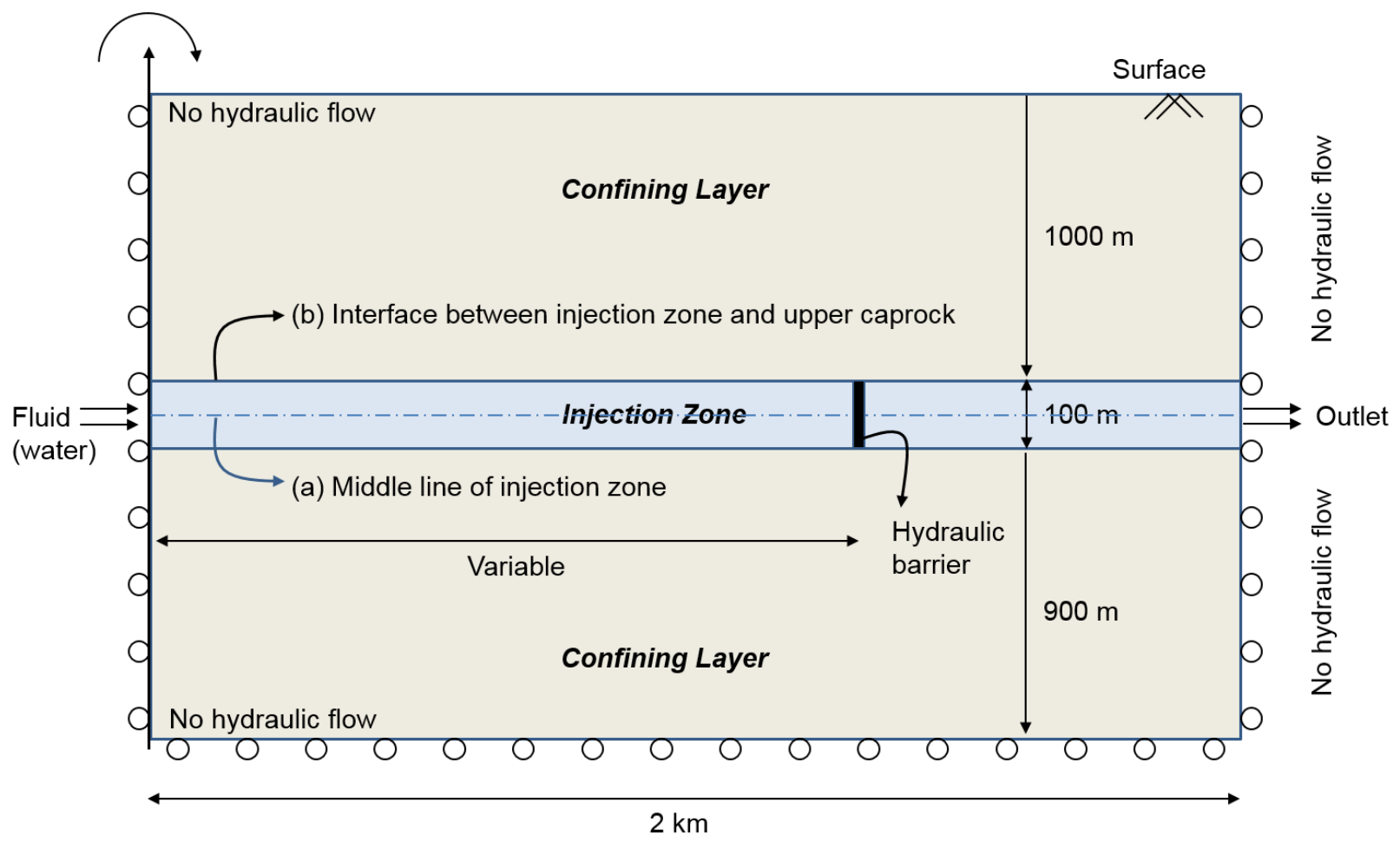

Fig. 3 Simulation model for numerical experiments in this study: geometry, lines of interest (center line of injection zone and interface between injection zone and upper caprock), and illustration of hydraulic barrier (activated at several realizations). 
(a)

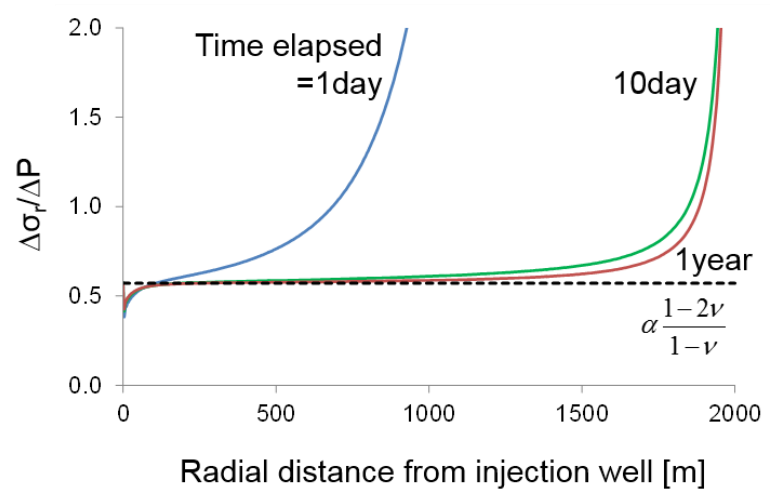

(c)

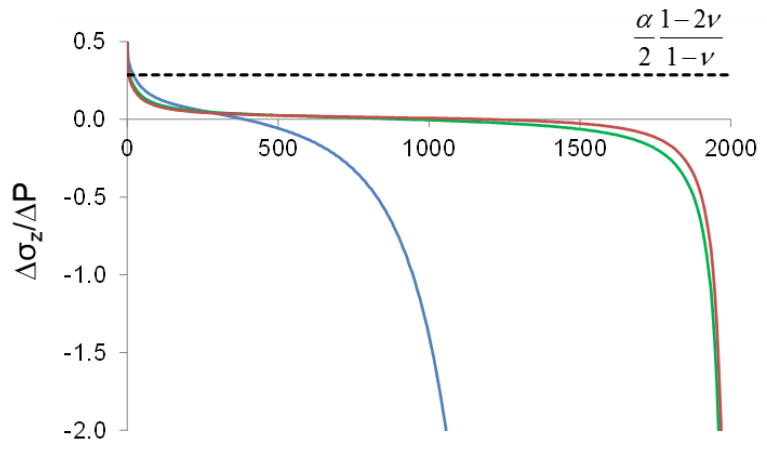

Radial distance from injection well [m] (b)

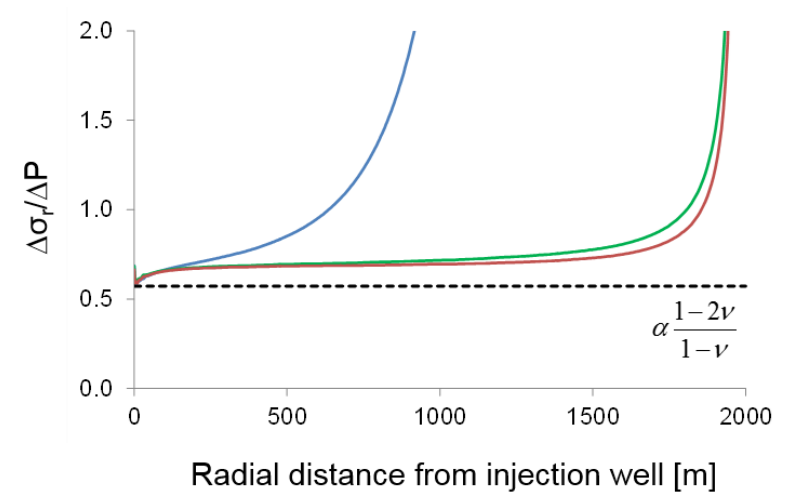

(d)

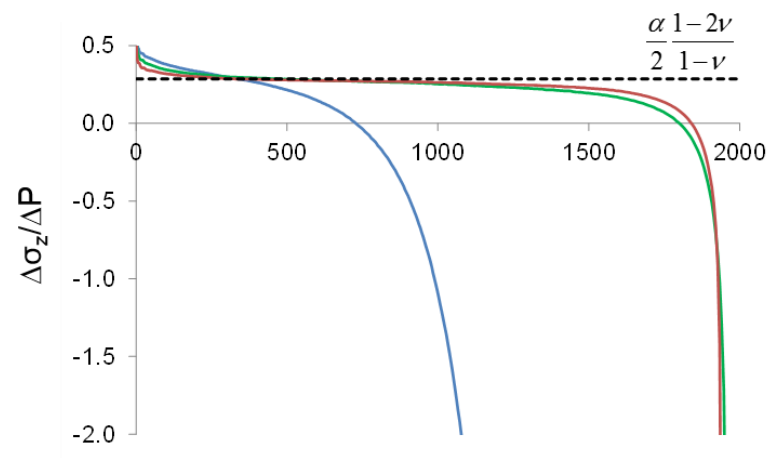

Radial distance from injection well $[\mathrm{m}]$

(e)

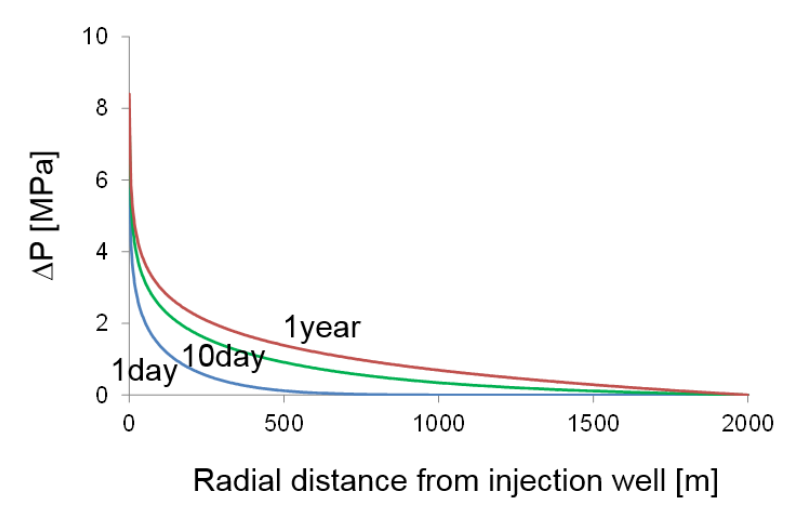

Fig. 4 Spatiotemporal evolution of pore-pressure/stress change ratios when hydraulic boundary of injection zone is open. (a) $\Delta \sigma_{r} / \Delta P$ at middle of injection zone, (b) $\Delta \sigma_{r} / \Delta P$ at interface between the injection zone and upper caprock, (c) $\Delta \sigma_{z} / \Delta P$ at middle, (d) $\Delta \sigma_{z} / \Delta P$ at interface, and (e) $\Delta P$ in the injection zone. Note: Blue line represents after time $t=1$ day, green line represents after $t=10$ days, and red line represents after $t=1$ year. $v=0.3, \varphi=0.25, \alpha=1$ for all layers, permeability of injection zone is $k_{I Z}=100 \mathrm{md}$, and permeability of upper caprock is $k_{c a p}=1$ nd. Other parameters as listed in Table 1. 


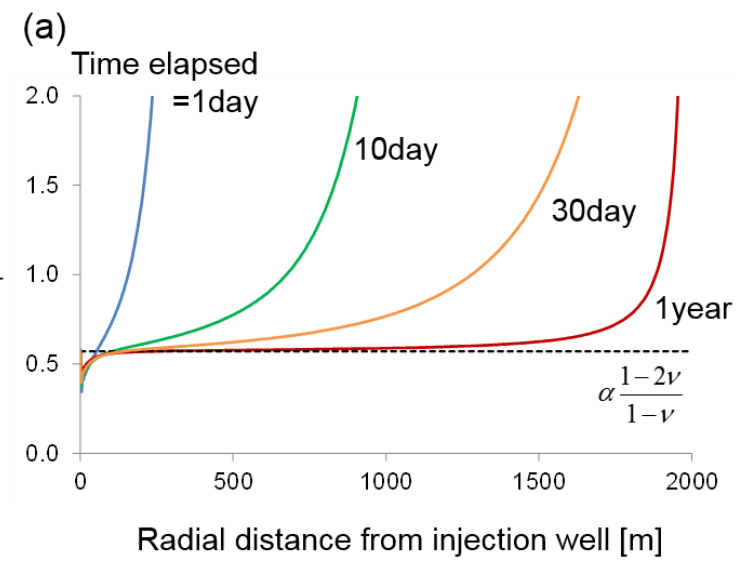

(c)

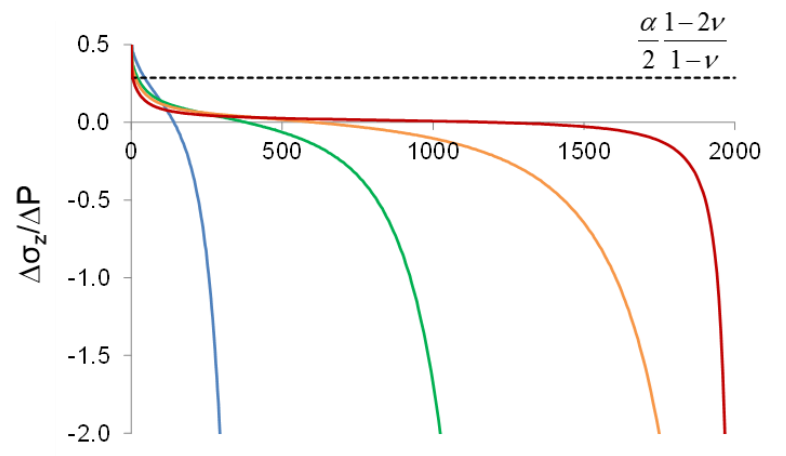

Radial distance from injection well [m]

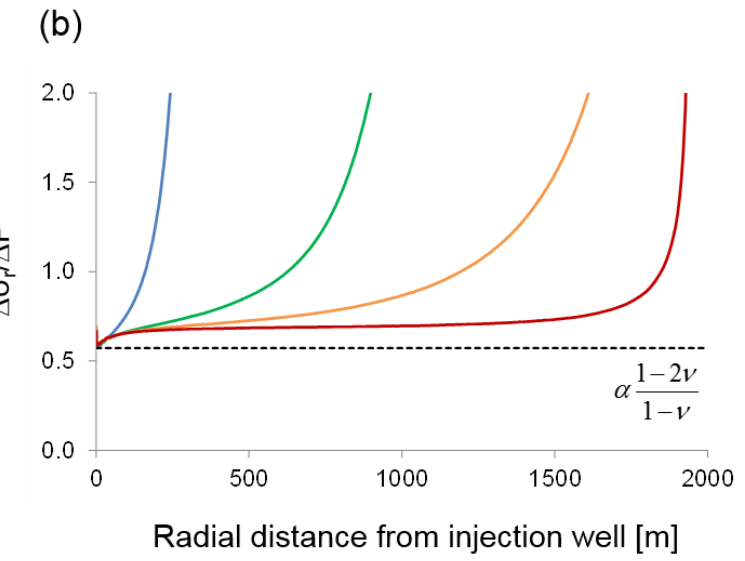

(d)

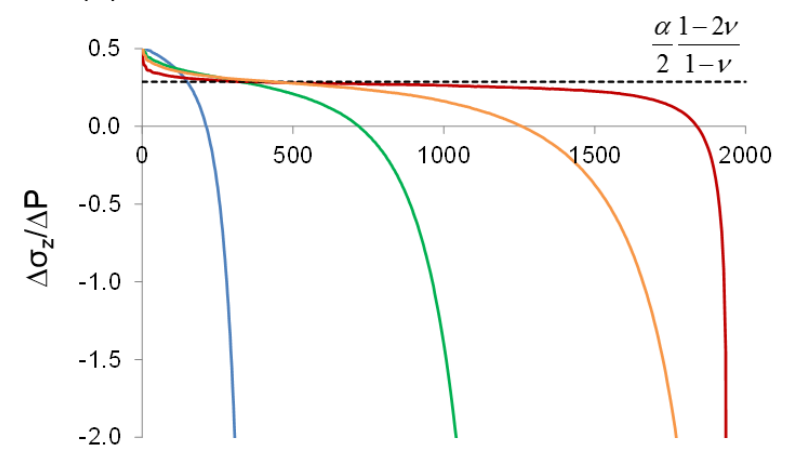

Radial distance from injection well [m]

(e)

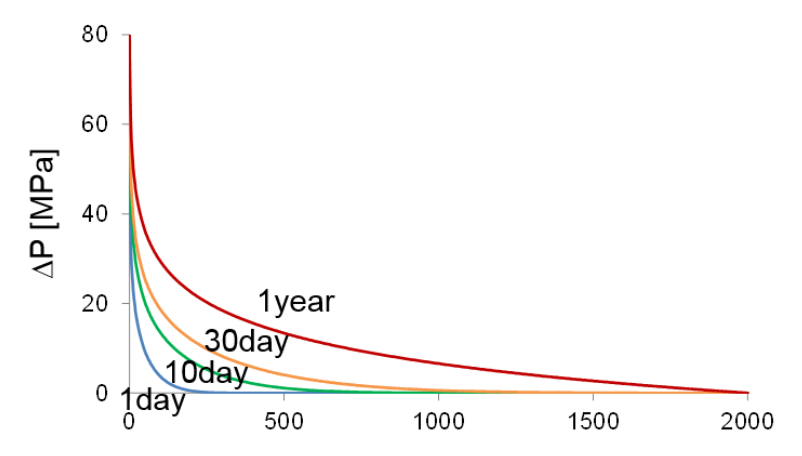

Radial distance from injection well [m]

Fig. 5 Spatiotemporal evolution of pore-pressure/stress change ratios when permeability of injection zone changes to $k_{I Z}=10 \mathrm{md}$ for open-end boundary condition. (a) $\Delta \sigma_{r} / \Delta P$ at middle, (b) $\Delta \sigma_{r} / \Delta P$ at interface, (c) $\Delta \sigma_{z} / \Delta P$ at middle, (d) $\Delta \sigma_{z} / \Delta P$ at interface, and (e) $\Delta P$ in injection zone. $v=0.3, \varphi=0.25, \alpha=1$ for all layers, and $k_{c a p}=1$ nd. Other parameters as listed in Table 1. 
(a)

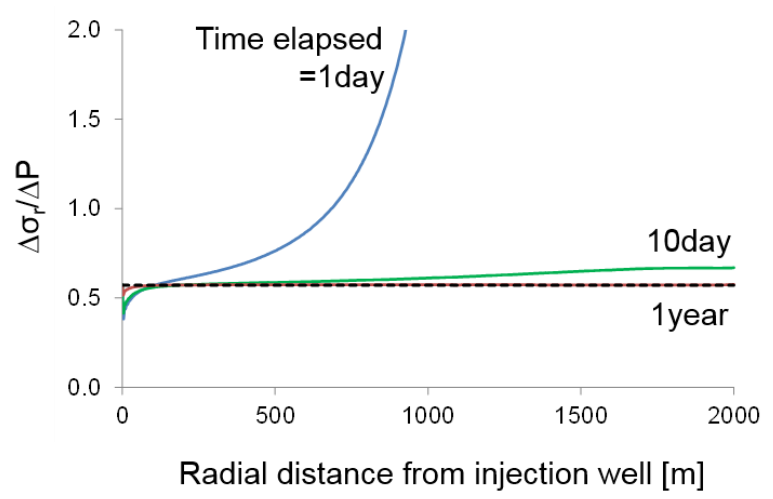

(c)

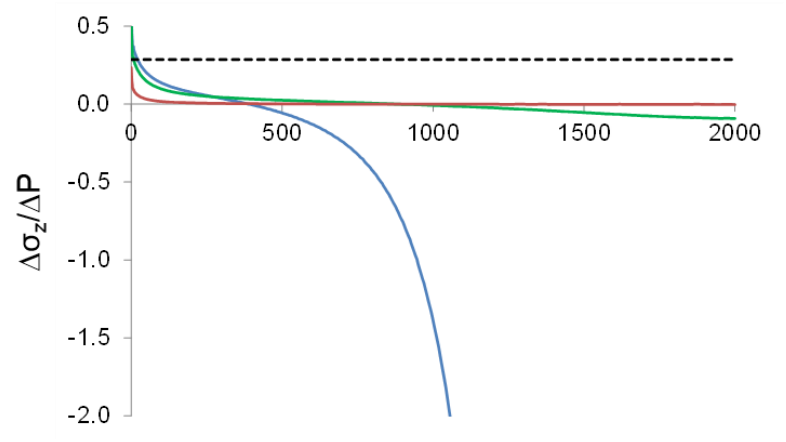

Radial distance from injection well [m] (b)

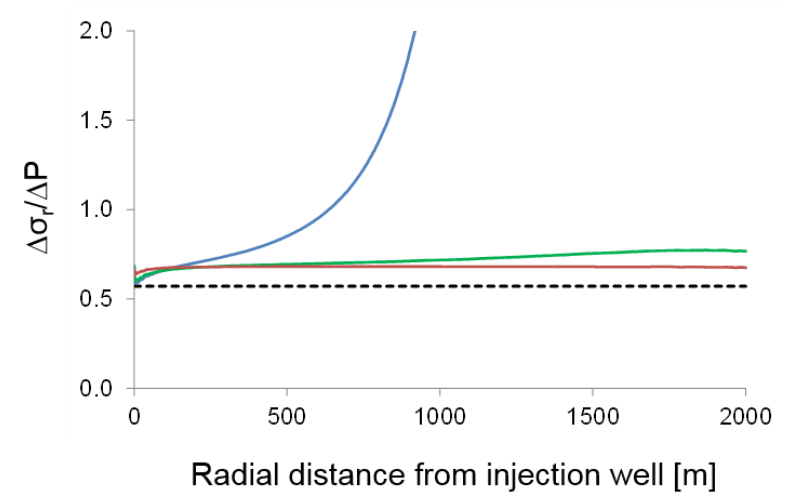

(d)

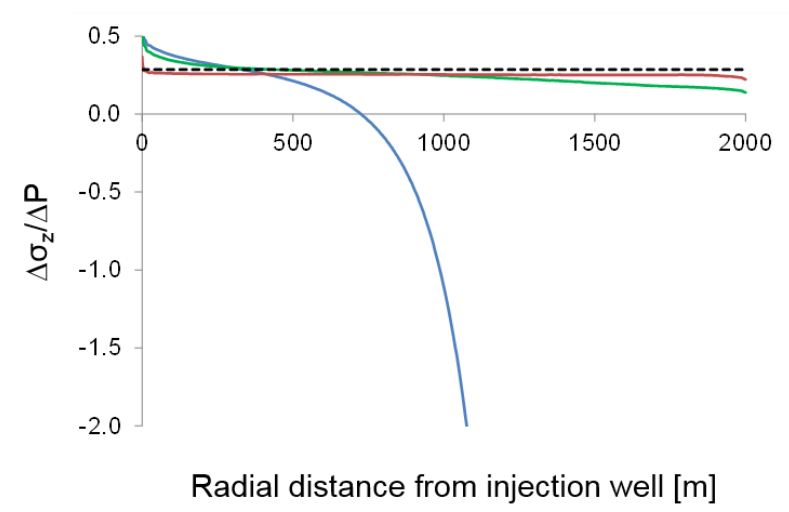

(e)

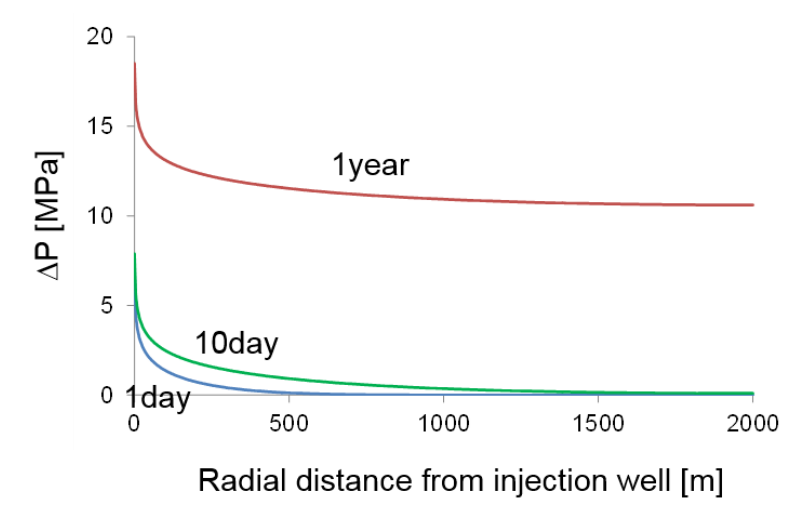

Fig. 6 Spatiotemporal evolution of pore-pressure/stress change ratios when hydraulic boundary of injection zone is closed. (a) $\Delta \sigma_{r} / \Delta P$ at middle, (b) $\Delta \sigma_{r} / \Delta P$ at interface, (c) $\Delta \sigma_{z} / \Delta P$ at middle, (d) $\Delta \sigma_{z} / \Delta P$ at interface, and (e) $\Delta P$ in injection zone. $v=0.3, \varphi=0.25$, $\alpha=1$ for all layers, $k_{I Z}=100 \mathrm{md}$, and $k_{\text {cap }}=1 \mathrm{nd}$. Other parameters as listed in Table 1. 
(a)

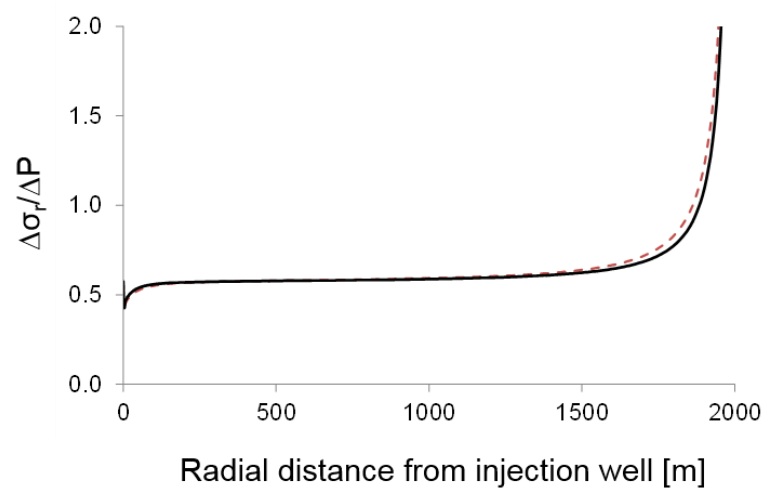

(c)

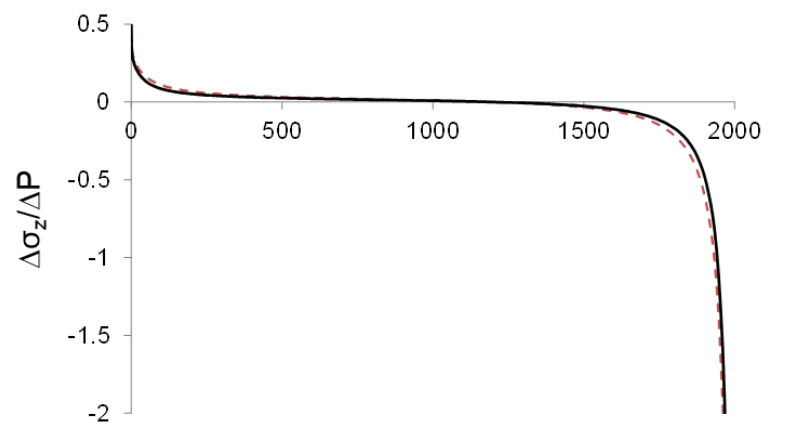

Radial distance from injection well [m] (b)

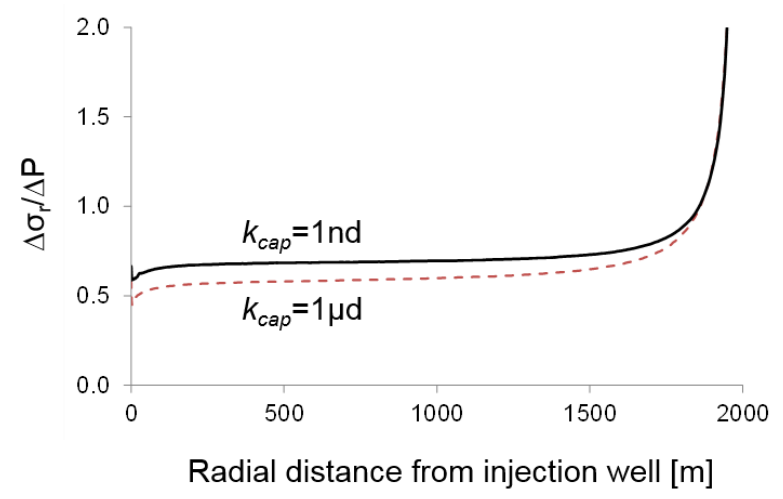

(d)

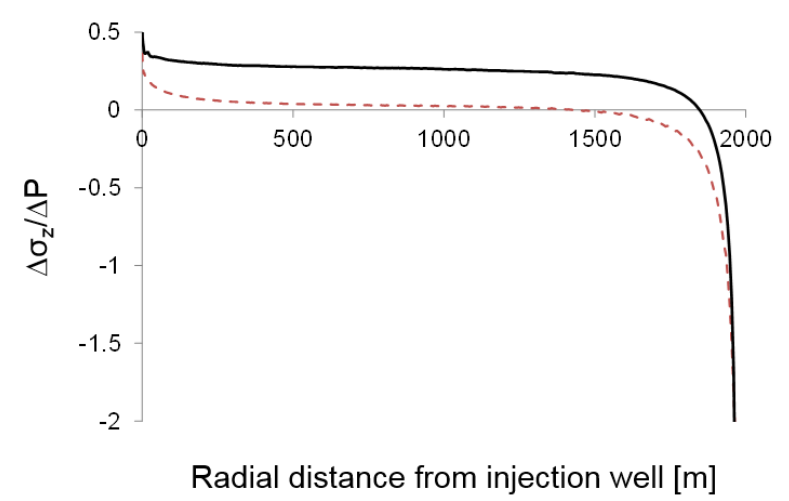

Fig. 7 Spatial evolution of pore-pressure/stress change ratios when permeability of caprock $k_{\text {cap }}$ varies. (a) $\Delta \sigma_{r} / \Delta P$ at middle, (b) $\Delta \sigma_{r} / \Delta P$ at interface, (c) $\Delta \sigma_{z} / \Delta P$ at middle, and (d) $\Delta \sigma_{z} / \Delta P$ at interface. Note: Solid line represents when $k_{c a p}=1 \mathrm{nd}$, and dashed line represents when $k_{c a p}=1 \mu \mathrm{d}$. $v=0.3, \varphi=0.25, \alpha=1$ for all layers, and $k_{I Z}=100 \mathrm{md}$. Other parameters as listed in Table 1 . Total simulation time $t_{\text {simul }}=1$ year. 
(a)

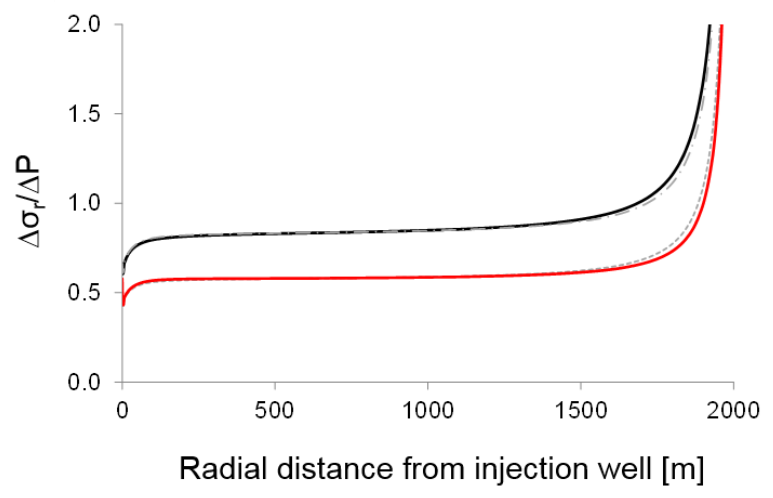

(c)

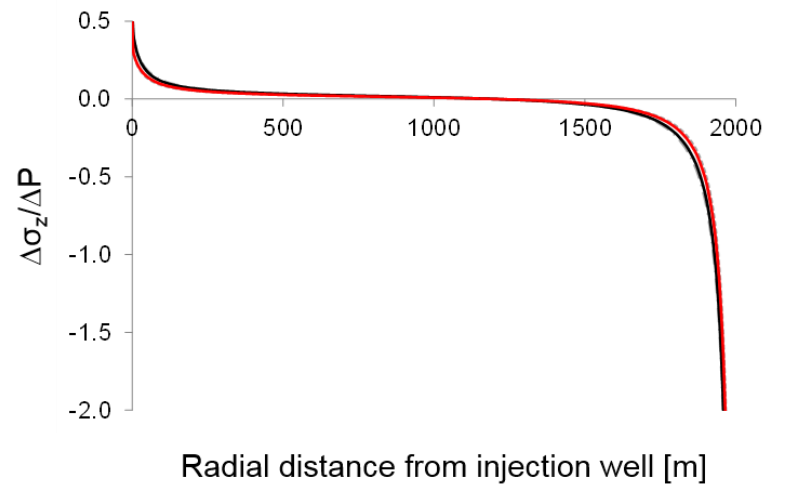

(b)

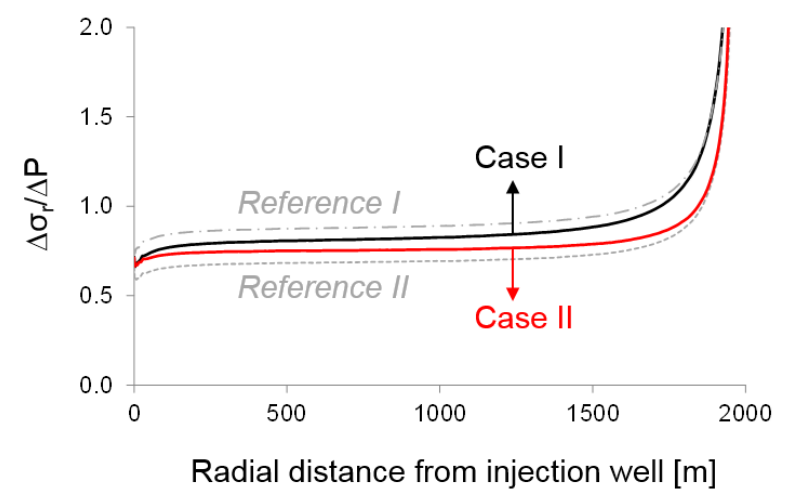

(d)

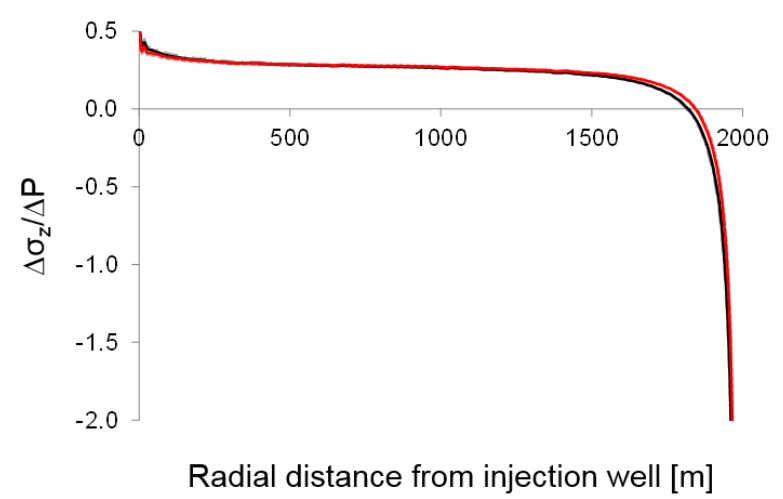

Fig. 8 Spatial evolution of pore-pressure/stress change ratios when Poisson's ratio differs between injection zone and upper caprock. (a) $\Delta \sigma_{r} / \Delta P$ at middle, (b) $\Delta \sigma_{r} / \Delta P$ at interface, (c) $\Delta \sigma_{z} / \Delta P$ at middle, and (d) $\Delta \sigma_{z} / \Delta P$ at interface. Note: Black solid line represents Case I while red solid line represents Case II. Dot-dashed line represents Reference I, and dashed line represents Reference II. $\varphi=0.25, \alpha=1$ for all layers, $k_{I Z}=100 \mathrm{md}$, and $k_{c a p}=1 \mathrm{nd}$. Other parameters as listed in Table 1. Total simulation time $t_{\text {simul }}=1$ year. 
(a)

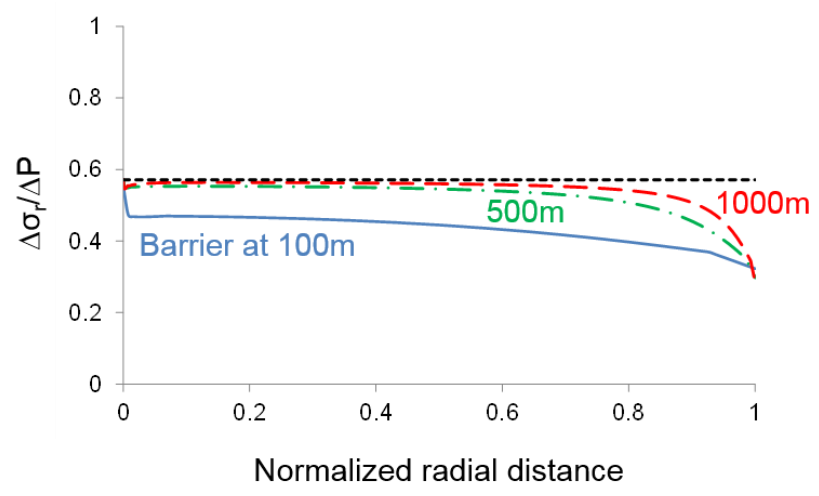

(c)

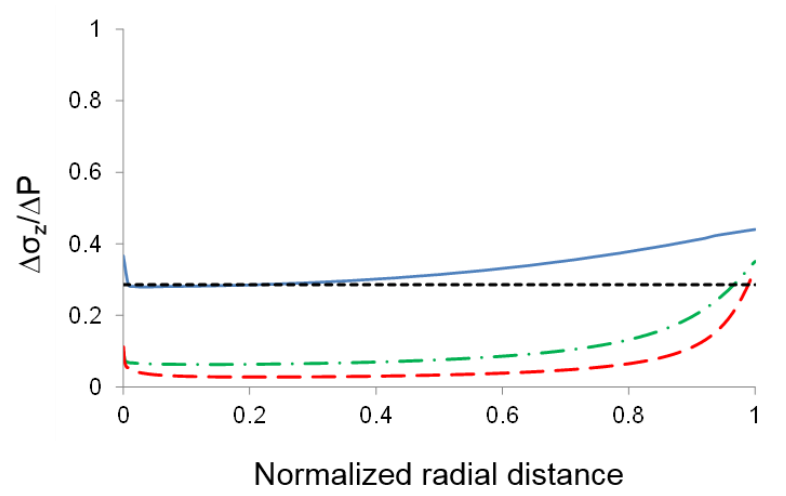

(b)

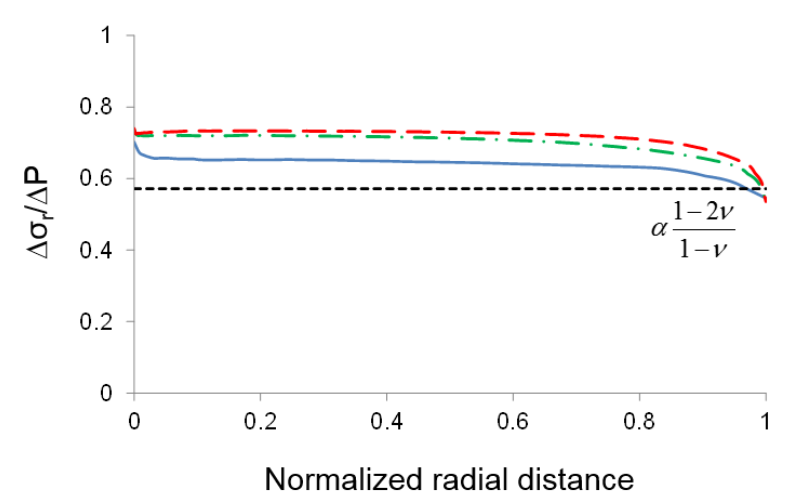

(d)

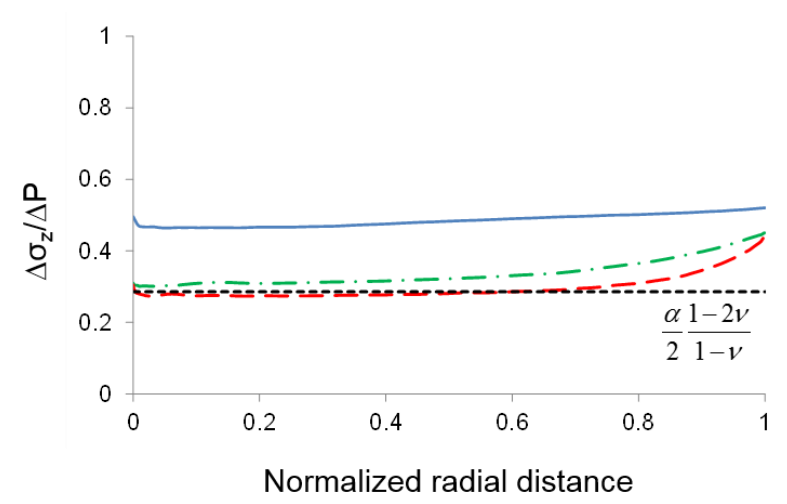

Fig. 9 Spatial evolution of pore-pressure/stress change ratios when hydraulic barrier exists in injection zone. (a) $\Delta \sigma_{r} / \Delta P$ at middle, (b) $\Delta \sigma_{r} / \Delta P$ at interface, (c) $\Delta \sigma_{z} / \Delta P$ at middle, and (d) $\Delta \sigma_{z} / \Delta P$ at interface. Note: Solid line represents when location of hydraulic barrier is $100 \mathrm{~m}$ away from injection well; dot-dashed line represents hydraulic barrier $500 \mathrm{~m}$ away; longer dashed line represents hydraulic barrier $1000 \mathrm{~m}$ away; and shorter dashed line represents long-term limit solution of homogeneous infinite model. $v=0.3, \varphi=0.25, \alpha=1$ for all layers, $k_{I Z}=100 \mathrm{md}$, and $k_{\text {cap }}=1 \mathrm{nd}$. Other parameters as listed in Table 1 . Total simulation time $t_{\text {simul }}=1$ year. 

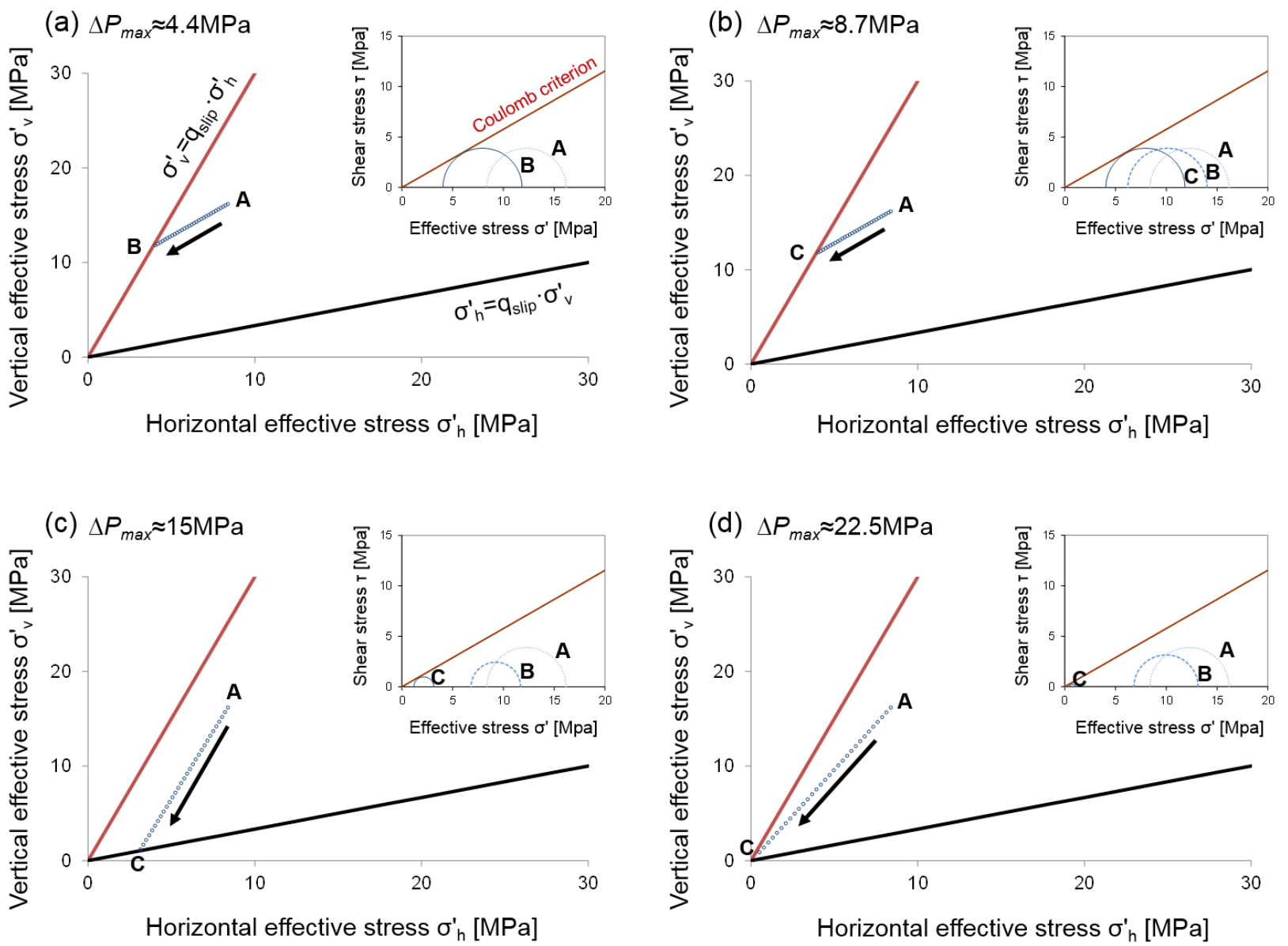

Fig. 10 Stress paths in effective stress $\sigma_{v}^{\prime}-\sigma_{h}^{\prime}$ space and corresponding Mohr circles with Coulomb failure criterion in the $\tau$ - $\sigma^{\prime}$ space for a storage reservoir of $K=\sigma_{h o} / \sigma_{v 0}=0.7$. (a) Traditional approach, (b) when $\beta_{h}=\beta_{v}=0.5$, (c) when $\beta_{h}=0.66, \beta_{v}=0$, and (d) when $\beta_{h}=0.66, \beta_{v}=0.33$. Note: Mohr circle $A$ represents initial stress state; $B$ denotes stress state after pore pressure increases by $\Delta P=4.4 \mathrm{MPa}$, maximum limit for traditional approach; and $C$ describes stress state at moment of shear slip after considering ratios of pore-pressure/stress changes differently in each scenario. 

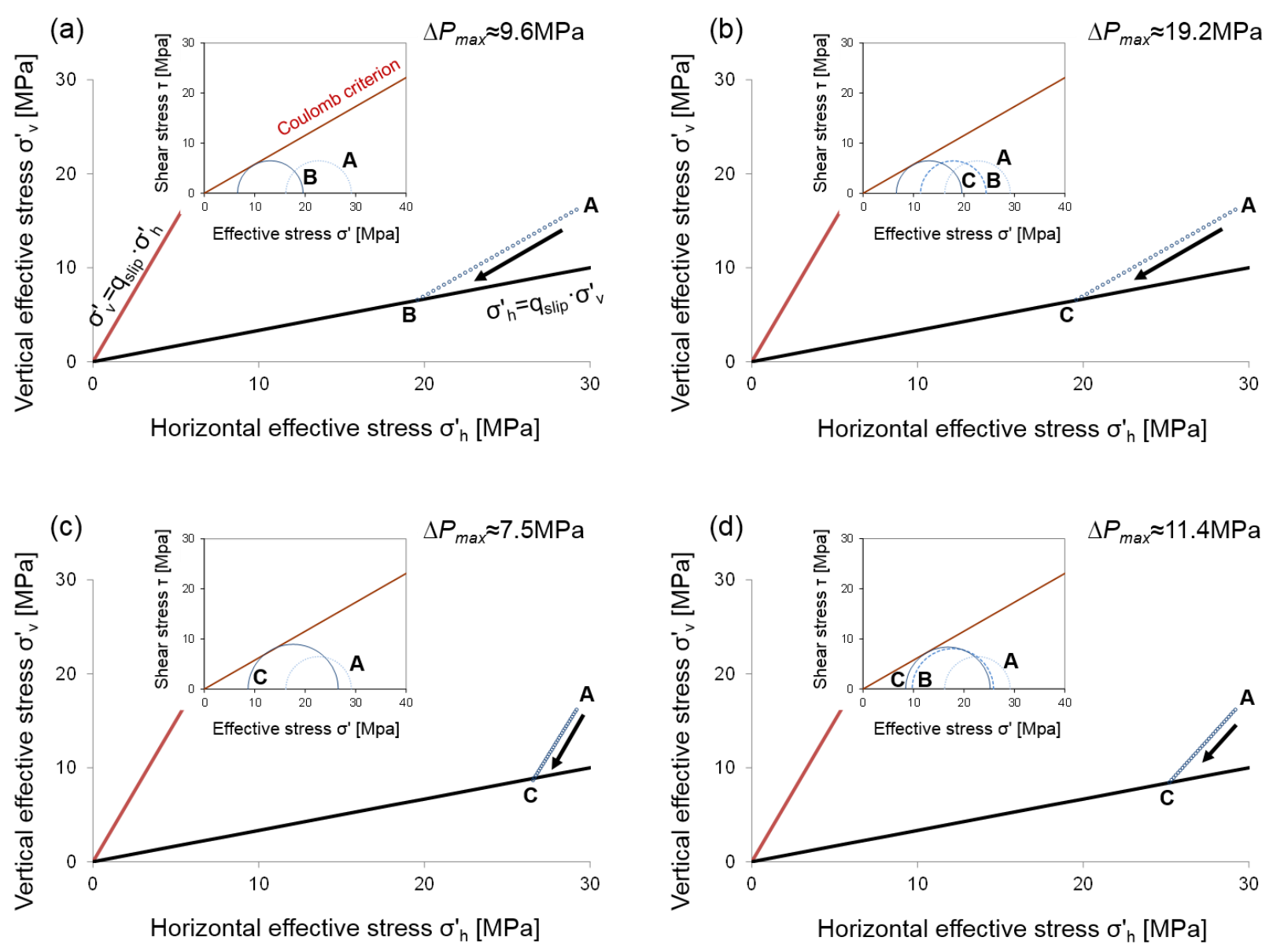

Fig. 11 Stress paths in effective stress space and corresponding Mohr circles for a storage reservoir of $K=\sigma_{h o} / \sigma_{v 0}=1.5$. (a) Traditional approach, (b) when $\beta_{h}=\beta_{v}=0.5$, (c) when $\beta_{h}=0.66, \beta_{v}=0$, and (d) when $\beta_{h}=0.66, \beta_{v}=0.33$. Note: Mohr circle $A$ represents initial stress state; $B$ denotes stress state after $\Delta P=9.6 \mathrm{MPa}$, maximum limit for traditional approach; and $C$ describes stress state at moment of shear slip after considering ratios of pore-pressure/stress changes differently in each scenario. 